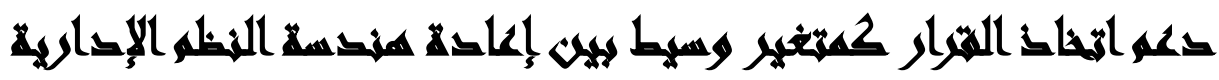

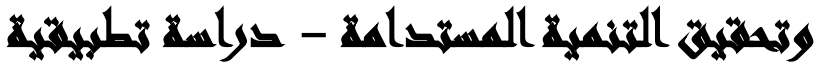

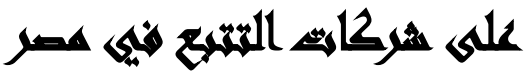

$$
\begin{aligned}
& \text { وليد محمد عبد الخالق بكر(')- محمود محمد عبد الهادي صبح(r)( } \\
& \text { موسي إبراهيم موسي("الي }
\end{aligned}
$$

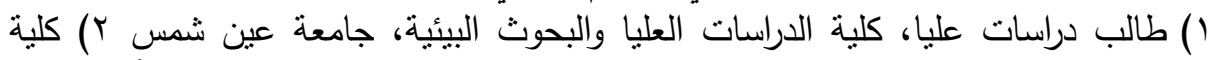

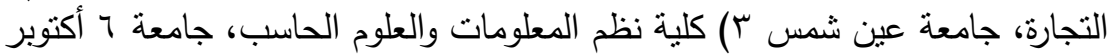

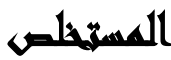

هدفت الدراسة للتعرف على دور النظم الادارية داخل شركات التتبع بجمهورية مصر

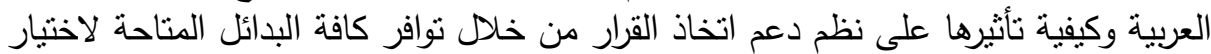

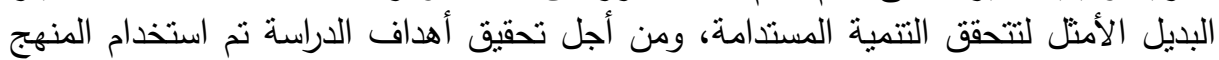

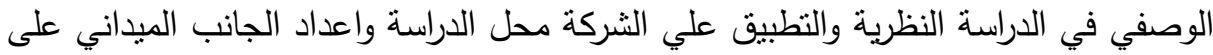
قائمة الاستبيان الموجهة لمفردات العينة والتي قامت الإني الدراسة باستخدام معادلة ستيفن ثامبسون

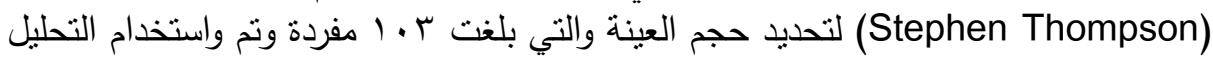
الاحصائي وذلك للتأكد من صحة الفروض للإراسة:

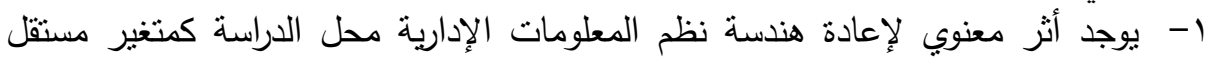

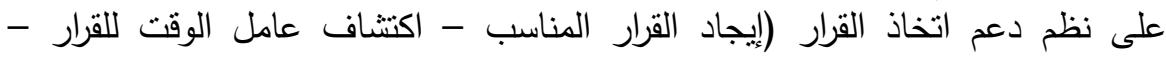
الصلاحية التفيذية للقرار ) كمتغير وسيط.

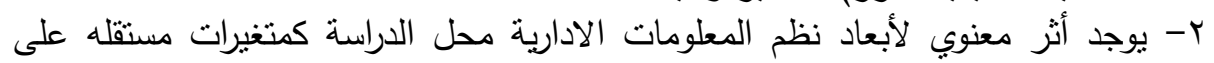

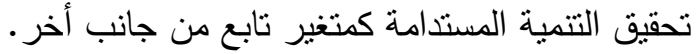

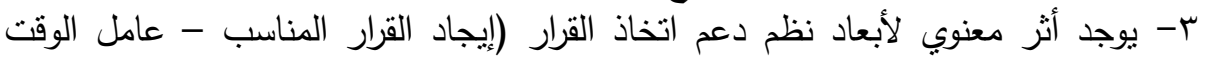

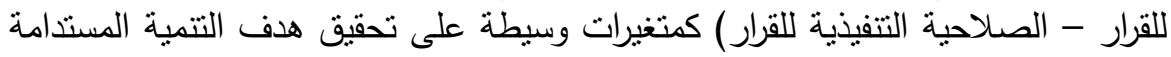
وذللك كمتغير تابع.

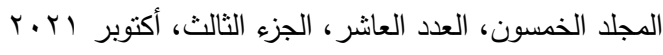

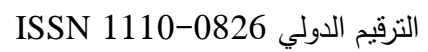

$$
\begin{aligned}
& \text { الترقيم الدولي الموحد الإلكتروني 3178-2636 }
\end{aligned}
$$


ومن أهم التوصيات التي يقدمها الباحثون ربط النظم الفرعية للشركات مع بعضها في بلتي

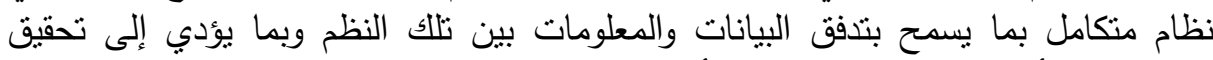

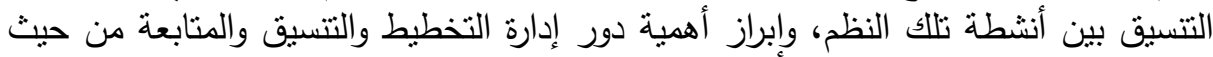

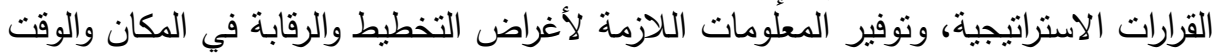
والثكل المناسب، والمتابعة والرقابة على عملية تداول البيانات والمعلومات وحفظها.

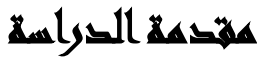

إن النطور السريع والمستمر في قطاع نظم المعلومات الادارية يلعب حالياً دوراً فعالاً في

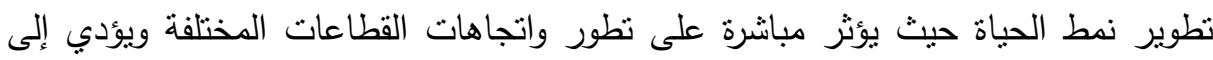

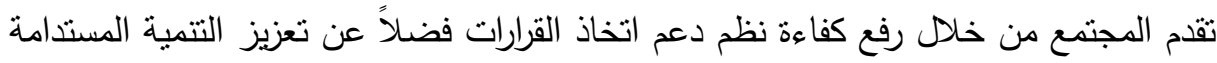

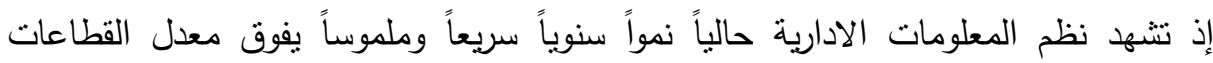

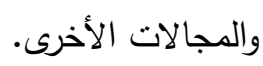

وذللك لأن هندسة نظم المعلومات الإدارية الجديدة قد تجعل طرق العمل الروتينية

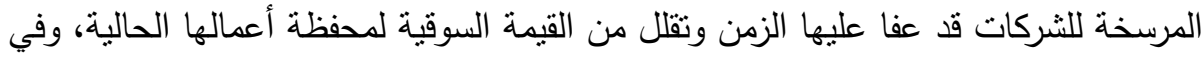

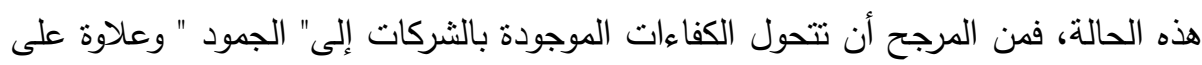

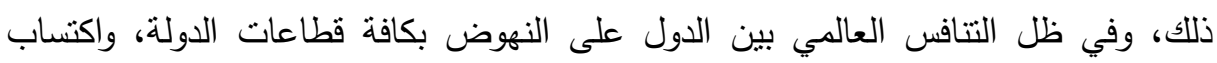

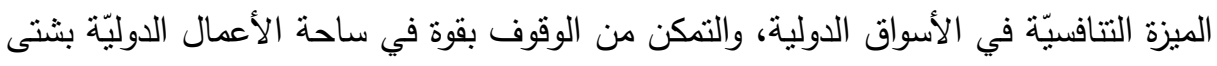

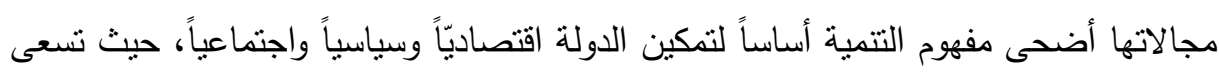
الدول إلى تحقيق التتمية المستدامة الداخليّة لنفسها بهدف الحفاظ على سيطرتها على مواردها الداخليّة وعلى حكمها، ومنع تدخل القوة الأخرى، والتي تهدف بشكل رئيسي إلى التى السيطرة عليها

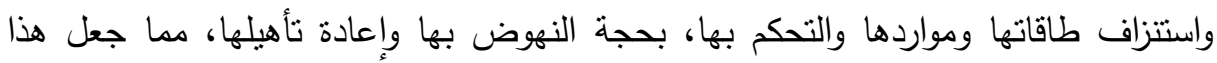

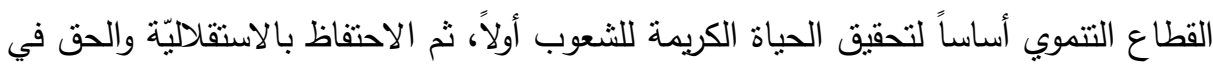

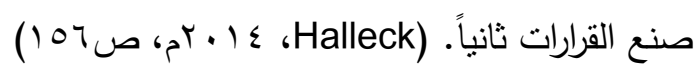

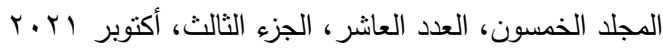

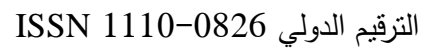

$$
\begin{aligned}
& \text { التزقيم الدولي الموحد الإلكتروني 3178-2636-2082 }
\end{aligned}
$$


تواجه المنظمات العالمية والمحلية العديد من التغيرات والتحديات سواء كانت منظمات

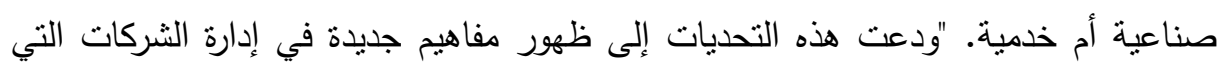
تسعى إلى تحقيق هدف البقاء والاستمرار في عالم المنافسة، وذلك بتغير أساليبها التقليدية التي لا تتتاسب مع ما نواجهه الثركات من تحديات، وتنبي مفاهيم إدارية حديثة تمكن المنظمة من التعامل مع التحديات التي توجهها والتغلب عليها لتحقيق مستوى الأداء الأفضل. (O^م) (Chen)

ولعل استخدام هذه الشركات لنظم المعلومات ذات كفاءة وفعالية من شأنه أن يحقق لها أهدافها، فقد نزايد الاهتمام بهذه النظم لما تلعبه من دور حاسم في تطوير الثركات ورفع

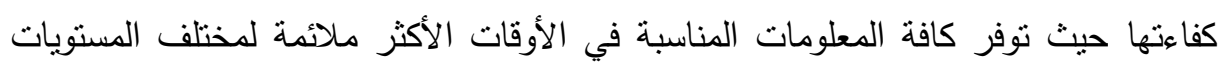
الإدارية، وذلك لدعم جميع المهام والوظائف الإدارية بالإضافة إلى تحسين وتطوير حركة الإنة الاتصالات وتدفق المعلومات بين تلك المستويات، وكل ذلك من شأنه أن ينعكس ايجابيا على والى الإنى

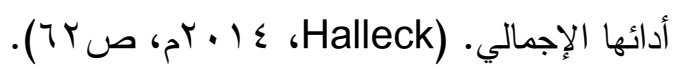

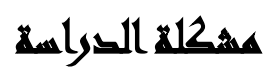

تسعى العديد من المنظمات المعاصرة (في ظل بيئة العمل الحالية التي تتميز بالطابع

التتافسي الثديد، والتغير التكنولوجي السريع، والعولمة المتزايدة) إلى تحسين مسنوى أداءها، وبناء ميزة تتافسية مستدامة على حساب غيرها من المنظمات العاملة في نفس النشاط

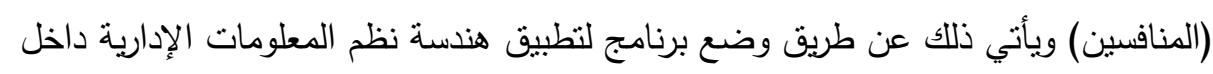

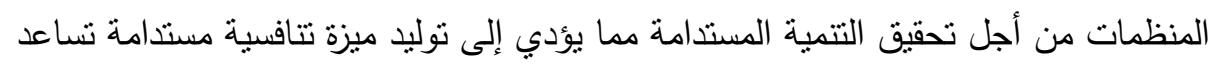
بقوة في تحقيق استراتيجية المنظمة.

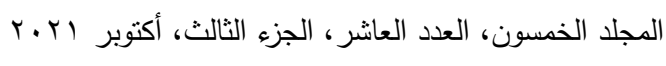

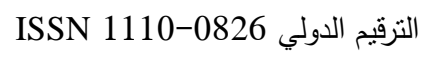

$$
\begin{aligned}
& \text { الترقيم الدولي الموحد الإلكتروني 3178-2636 }
\end{aligned}
$$


وقد أجري الباحثون بدراسة استطلاعية للوقوف على مشكلة الدراسة وأبعادها المختلفة

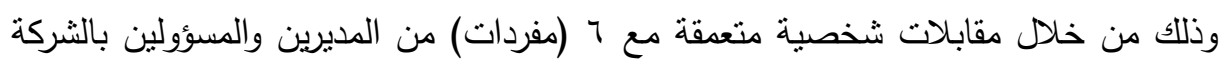

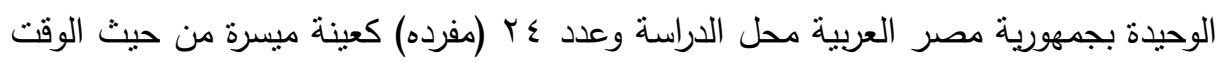
والجهر والتكلفة من العاملين بالثركة محل الدراسة. وقد قامت الدراسة الاسنطلاعية بهدف تحديد ومعرفة درجة تطبيق الثركة محل الدراسة

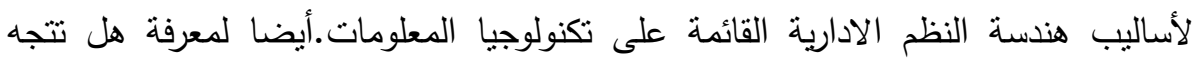

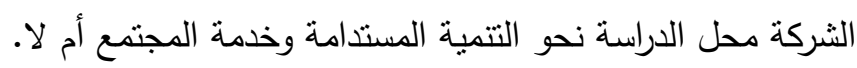
وكانت النتيجة أن هناك مشكلة حقيقية وراء تلك الظواهر ومن أهم هذه الظواهر ما يلي: 1. ضعف الاعتماد على هندسة النظم الادارية القائمة على تكنولوجيا المعلومات. r. عدم تتمية وتطوير الكوادر والكفاءات البشرية وحثها على الابتكار بالثكل المطلوبه الثله بالثركة محل الدراسة. r. عدم خلق بيئة عمل يمكن أن تحفز روح المبادرة وتتمية الكفاءات والكوادر للعاملين بالثركة محل الدراسة. ومن هنا برز دور إعادة تطبيق هندسة نظم المعلومات الادارية وتحقيق استراتيجية

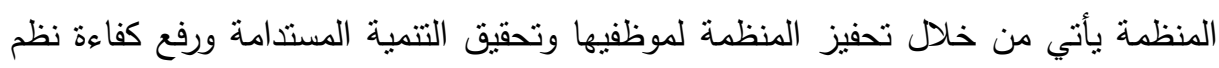
دعم اتخاذ القرارات بالثركة محل الدراسة، وخلق بيئة يمكن أن تحفز روح المبادرة وتتمية

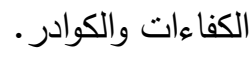
وأثناء تتفيذ الدراسة الاستطلاعية تنين الحاجة الي عمل مقابلات مع عدد من مديري

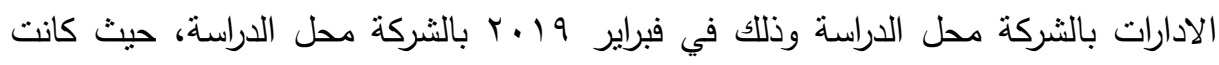

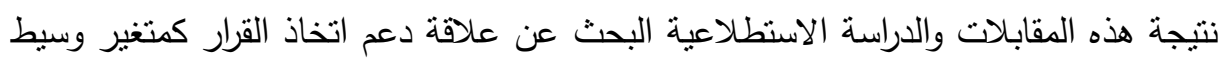

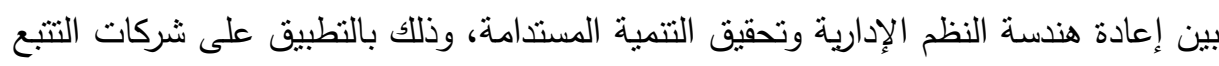
في مصر

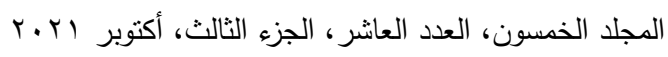

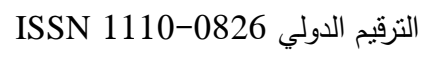

$$
\begin{aligned}
& \text { الترقيم الدولي الموحد الإلكتروني 3178-2636 }
\end{aligned}
$$


مجلة العلوم البيئية

كلية الدراسات العليا والبحوث البيئية - جامعة عين شمس البئة

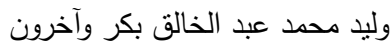

\section{أسئلا الصواسما}

ا ـ إلى أب مدى تعتمد نظم دعم القرار على نظم المعلومات الادارية؟

r. ما دور النظم الادارية القائمة على تكنولوجيا المعلومات في دعم إدارة التتمية المستدامة؟ لفي

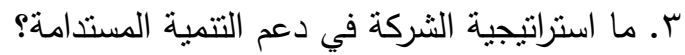

\section{هزوزه التواسمة}

الفرض الأول: يوجد أثز معنوي لإعادة هندسة نظم المعلومات الإدارية محل الدراسة كمتغير

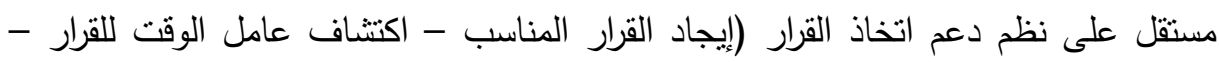

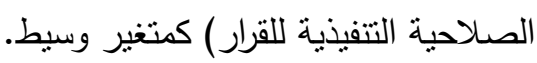
الفرض الثاني: يوجد أثز معنوي لأبعاد نظم المعلومات الادارية محل الدراسة كمتغيرات مستقله على تحقيق التتمية المستدامة كمتغير تابع من جانب أخر . الفرض الثالث: يوجد أثر معنوي لأبعاد نظم دعم اتخاذ القرار (إيجاد القرار المناسب من - عامل الوقت للقرار - الصلاحية التفيذية للقرار) كمتغيرات وسيطة على تحقيق هدف التتمية المستدامة وذللك كمتغير تابع.

\section{أهمية القواسمة}

الأهمية العلمية: تستمد هذه الدراسة أهميتها من العوامل التالية:

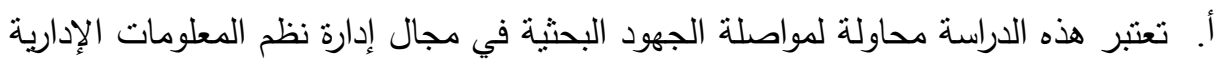
التي من دورها دعم نظم اتخاذ القرار وتحقيق التتمية المستدامة داخل المنظمات العربية

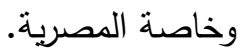

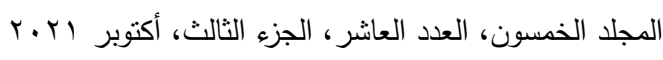

$$
\begin{aligned}
& \text { التزقيم الدولي } \\
& \text { الترقيم الدولي الموحد الإلكتروني 3178-2636-2كان }
\end{aligned}
$$




$$
\text { مجلة العلوم البيئية }
$$

كلية الدراسات العليا والبحوث البيئية - جامعة عين شمس لئن

وليد محمد عبد الخالق بكر وآخرون الئه

ب. توفر الدراسة أساس للمقارنة يمكن استخدامه من قبل الدراسات المستقبلية حيث لم يسبق

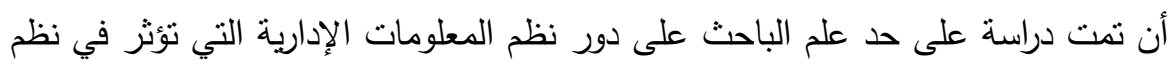

دعم القرارات ليتحقق هدف التتمية المستدامة.

الأهمية التطبيقية: شركات التتبع بجمهورية مصر العربية حيث أنها من الثركات الرائدة التي تهدف الي أهداف اجتماعية وليست اقتصادية لتحقيق بيئة نظيفة ذات تتمية مستدامة.

\section{أهمانهم الترواسمة}

ا ـ التعرف على دور النظم الادارية في نظم دعم اتخاذ القرار.

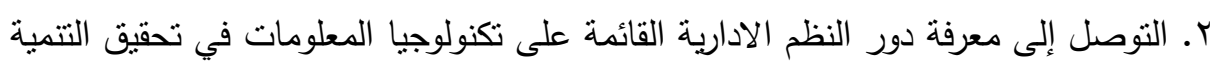
المستدامة.

r. التوصل الي استراتيجية الثركة في دعم التتمية المستدامة.

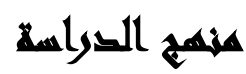

المنهج الوصفي: سعيا نحو تحقيق أهداف الدراسة واختبار فروضها، اعتمد اجراء هذه الدراسة على الأسلوب الوصفي التحليلي الكمي، والذي يقوم على وصف، وتحليل الظاهرة

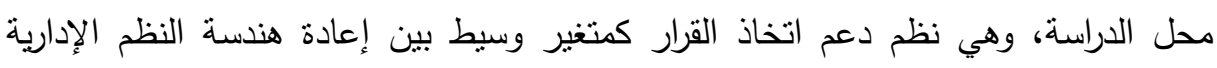

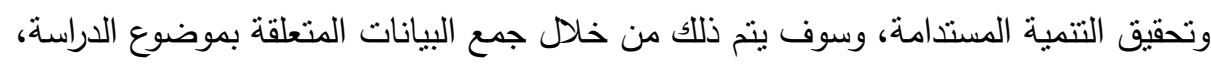
وذللك بتصميم قائمة استقصاء واحدة تغطي الجوانب المتعلقة بمتغيرات الدراسة، وذلك الك

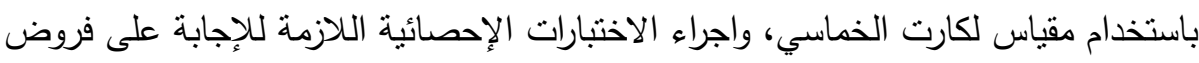
الدراسة، ومن ثم تحليل النتائج بما يخدم أهداف الدراسة.

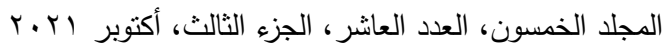

$$
\begin{aligned}
& \text { الترقيم الدولي 0826-08SN 1110 } \\
& \text { الترقيم الدولي الموحد الإكتروني 3178-2636 }
\end{aligned}
$$




\section{إبراءائ التراسة}

\section{أولا: مصطلحات الدراسة}

نظم دعم اتخاذ القرار: هي أنظمة معلومات لمستوى الإدارة تقوم بربط الييانات والنماذج

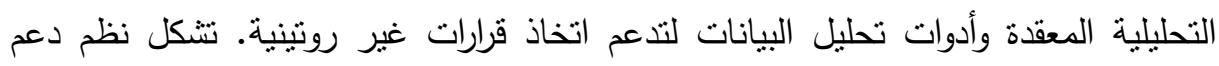

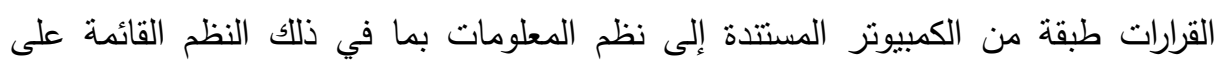
المعرفة التي تدعم أنشطة صنع القرار . هي أنظمة هدفها الرئيسي مساعدة المقررين عند اتخاذ القرار سواء من ناحية البحث

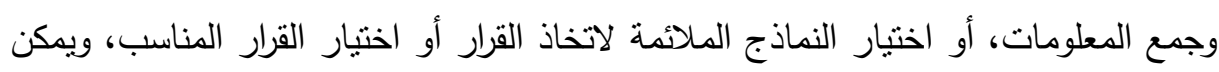

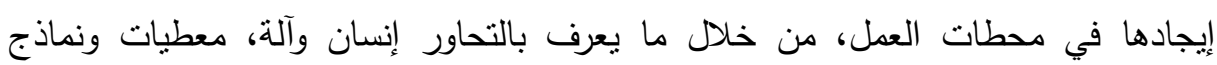

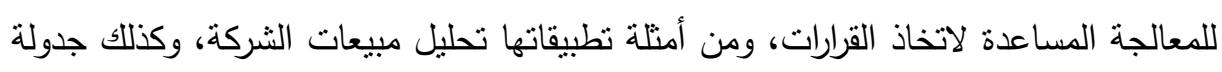
الإنتاج، وتحليل التكاليف والأسعار والأرباح، إضافة إلى تكاليف العقود. (4Puerta)

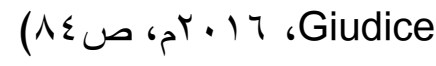
تكنولوجيا المعلومات الإدارية: هو علم ذات طابع تكنولوجي إداري حديث مهم في العصر الحال

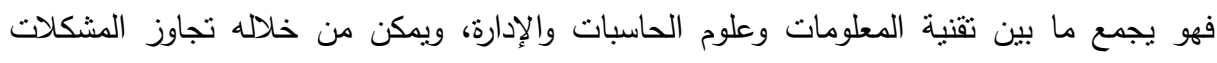

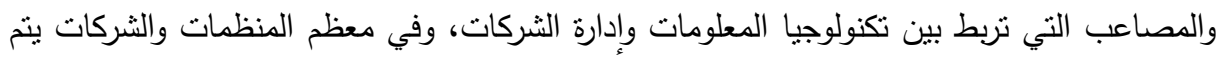

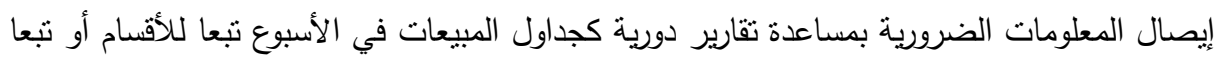
لطبيعة الزبائن، وتحليل التكاليف، والموازنات الثهرية والسنوية مع الانحرافات، وفي أغلب النئ الأحيان يثكل النظام المحاسبي الركيزة لهنل هذه التقارير، ويمكن أن توضح بطريقة نظامية تبعا لفترة دورية محددة سابقا أو بناء على طلب المستعطلين: () الجانب المادي: ويتكون من معدات الحاسوب والتحكم الأتوماتيكي وتكنولوجيا الاتصالات.

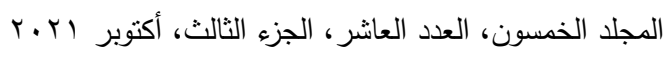

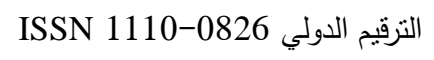

$$
\begin{aligned}
& \text { الترقيم الدولي الموحد الإلكتروني 3178-2636 }
\end{aligned}
$$


r) الجانب الذهني: ويتكون من البرمجيات والذكاء الاصطناعي وهندسة البرمجيات والموارد البشرية والكوادر المدربة على استخدام قواعد البيانات وتكنولوجيا المعلومات الإدارية.

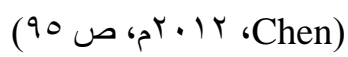

التنمية المستدامة: هي عملية تطوير الأرض والمدن والمجتمعات وكذللك الأعمال التجارية بشرط ان تلبي احتياجات الحاضر بدون المساس بقدرة الأجيال القادمة على تلبية حاجاتها.

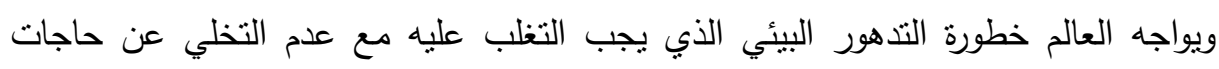

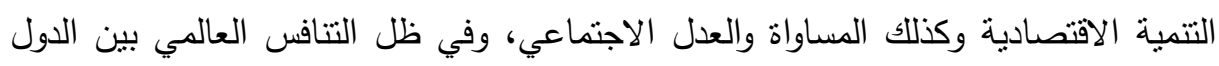

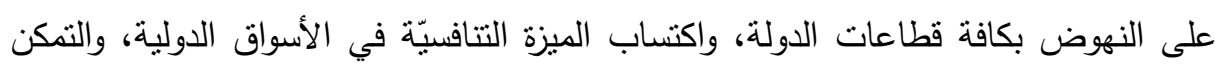
من الوقوف بقوة في ساحة الأعمال الدوليّة بشتى مجالاتها أضحى مفهوم التتمية أساساً لتمكين الدولة اقتصاديًاً وسياسياً واجنماعياً، حيث تسعى الدول إلى تحقيق التتمية المستدامة الداخليّة

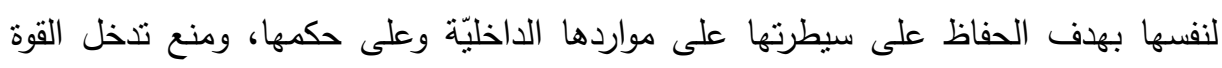
الأخرى، والتي تهدف بشكل رئيسي إلى السيطرة عليها واستنزاف طاقاتها ومواردها والتحكم

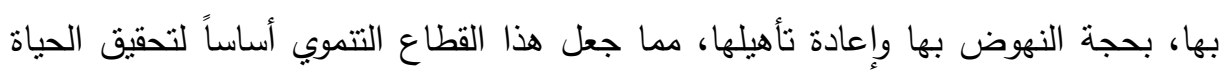

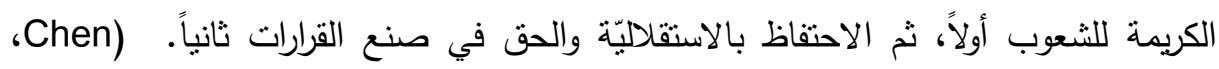

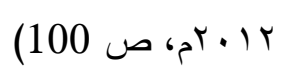

التنمية: من أهم المفاهيم العالمية في القرن العشرين، حيث أُطلق على عملية تأسيس نظم

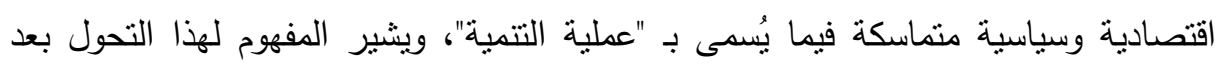
الاستقلال -في الستينيات من هذا القرن-في آسيا وإفريقيا بصورة جلية. وتبرز أهمية مفهوم

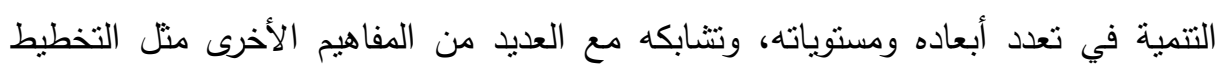
والإنتاج والتقدم. 
الاستدامة: الاستدامة هي مصطلح بيئي يصف كيف تبقى النظم الحيوية متتوعة ومنتجة مع

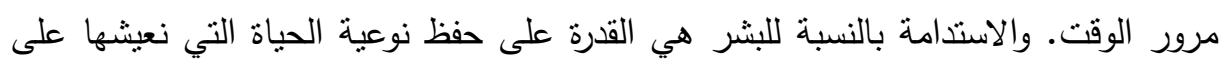
المدى الطويل وهذا بدوره يعتمد على حفظ العالم الطبيعي والاستخدام المسؤول للموارد

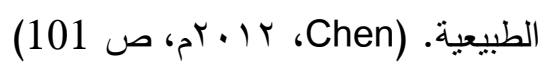
خدمات التتبع: تعد هذه الخدمة إحدى الطفرات التكنولوجية التي تحقق مزيدا من الكفاءة

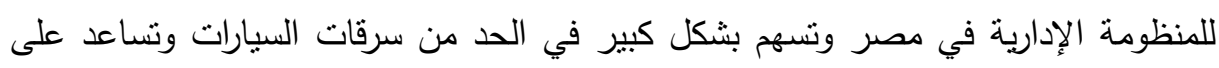
نمو العديد من القطاعات مثل النقل والبترول وغيرهما، كما إن هذه الخدمة تتيح للمشتركين

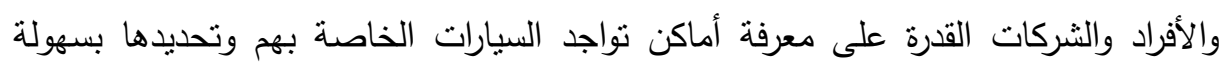

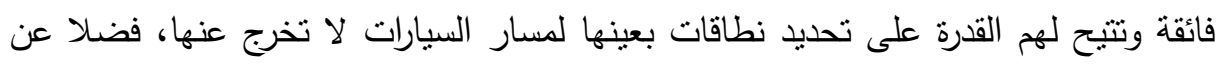

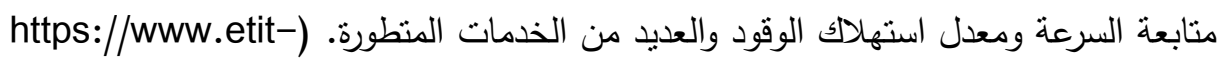
(ETIT، 2013 ،eg.com/index-ar.html ثانيا: الدراسات السابقة: نم نقسيم الدراسات السابقة إلى ثلاث اجزاء كما يلي: الجزء الأول: تتاول نظم دعم اتخاذ القرار القائم على تكنولوجيا المعلومات الادارية.

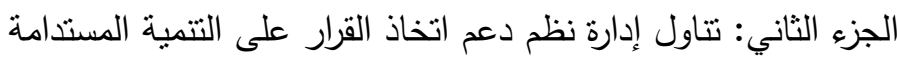
الجزء الثالث: تتاول إدارة تكنولوجيا المعلومات الادارية على نظم دعم اتخاذ القاد القرار والتتمية المستدامة

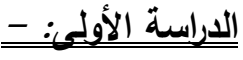

المؤلف: البكري، سونيا محمد. نظم المعلومات الإدارية جامعة الإسكندرية. قسم ادارة

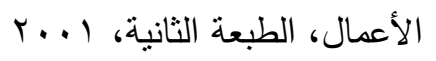

الهدف: معرفة مدى استخدام نظم المعلومات الإدارية في صنع القرارات الإدارية في

التزقيم الدولي

$$
\text { التزقيم الدولي الموحد الإلكتروني 3178-2636 النيم }
$$




$$
\begin{aligned}
& \text { مجلة العلوم البيئية - مالية } \\
& \text { كلية الدراسات العليا والبحوث البيئية - جامعة عين شمس لئس } \\
& \text { وليد محمد عبد الخالق بكر وآخرون }
\end{aligned}
$$

المجال: بحث مقدم لمؤتمر المنظمة العربية للمسئولين عن القبول والتسجيل في الجامعات

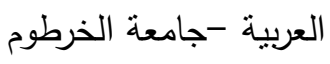

النتيجة: ان نظم المعلومات الإدارية يجب أن تصنف وفق المهام الإدارية التي تتعلق بها

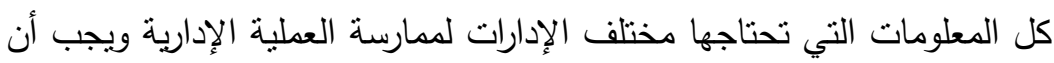

$$
\begin{aligned}
& \text { تكون دقيقة. } \\
& \text { الاراسة الثانية: - }
\end{aligned}
$$

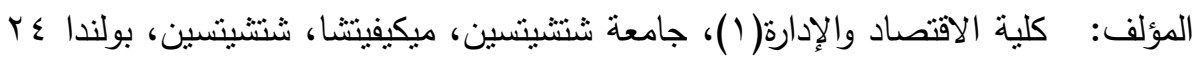

$$
\text { فبراير } 9 \text { ب. }
$$

الهدف: دعم اتخاذ القرار على أساس التبعيات بين المعايير في الإدارة المستدامة لطاقة

$$
\text { الرياح }
$$

مجال كلية الاقتصاد والإدارة، جامعة شنتيتسين، ميكيفيتشا، شتشينسين، النطبيق:

النتيجة: الاختيار الرسمي لطريقة MCDA لمشاكل اتخاذ القرار في مجال الدقة والاستدامة، بناءً على تحليل الخصائص الجوهرية للطرق الفردية، باستخدام

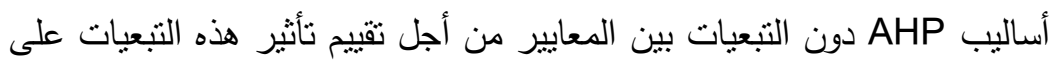

$$
\text { الحل الذي تم الحصول عليه. }
$$

الادراسة الثالثة: - الثئ

المؤلف: ريتشارد واتسون(r) -قسم نظم المعلومات الإدارية، كلية ادارة الأعمال بالولايات

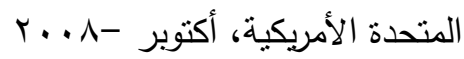

(1) Faculty of Economics and Management, University of Szczecin, Mickiewicz a 64, 71-101 Szczecin, Poland 24 February 2019

(2) Halleck, K. Designing routes of development of renewable energy technologies. Procardia Soc. Behave. Sci. 2014, 156, 58-62. [Google Scholar] [CrossRef].

$$
\begin{aligned}
& \text { المجلد الخمسون، العدد العاثر ، الجزء الثالث، أكتوبر ا Y. r. }
\end{aligned}
$$

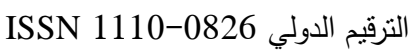

$$
\begin{aligned}
& \text { الترقيم الدولي الموحد الإكتروني 3178-2636 }
\end{aligned}
$$




$$
\text { مجلة العلوم البيئية }
$$

كلية الدراسات العليا والبحوث البيئية - جامعة عين شمس البئة

وليد محمد عبد الخالق بكر وآخرون

الهدف: اتخاذ القرارات متعددة المعايير لتقييم واختيار مشاريع نظم المعلومات وتطوير

$$
\text { منظور الاستدامة }
$$

مجال امعة جورجيا، أثينا، جورجيا، الولايات المتحدة الأمريكية

النتيجة: تحتاج المنظمات إلى الاستعداد للتغييرات في كل من العقلية والسلوك. أولاً،

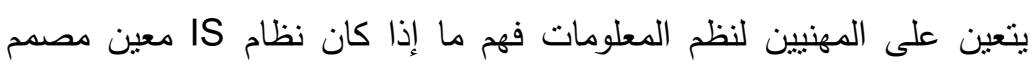

$$
\text { للكفاءة أو الفعالية، من أجل كبح التدهور البيئي. }
$$

الإساسة الرابعة:

المؤلف: ريتشارد وانسون-قسم نظم المعلومات الإدارية، كلية ادارة الأعمال بأمريكا، اكتوبر

$$
\text { r.l. }
$$

الهدف: نظم المعلومات والتتمية المستدامة والاتجاهات الجديدة للمجتمع

مجال مركز أبحاث نظم المعلومات الإدارية، جامعة مينيسوتا التطبيق:

النتيجة: تطوير ممارسات تجارية مستدامة بيئًا. على وجه التحديد، وبصفتتا باحثون

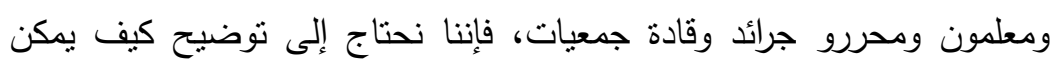

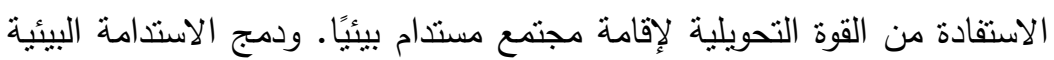

$$
\text { كأساس هام في تعليمهم وفي مبادئهم الأساسية. }
$$

$$
\text { الدراسة الخامسة: - }
$$

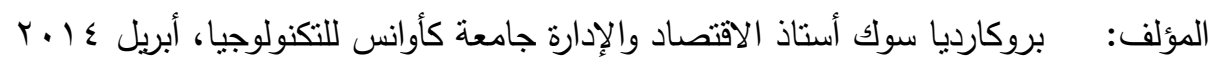
الهدف: تصميم طرق تطوير تقنيات الطاقة المتجددة

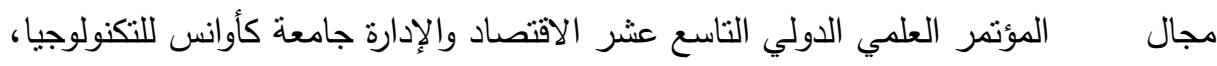
التطبيق: بياليستوك، بولندا

$$
\begin{aligned}
& \text { المجلد الخمسون، العدد العاشر ، الجزء الثالث، أكتوبر ب.r.r. }
\end{aligned}
$$

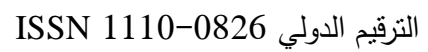

$$
\begin{aligned}
& \text { التزقيم الدولي الموحد الإلكتروني 3178-2636-26 التروي }
\end{aligned}
$$




\section{مجلة العلوم البيئية \\ كلية الدراسات العليا والبحوث البيئية - جامعة عين شمس لئن \\ وليد محمد عبد الخالق بكر وآخرون الئن}

النتيجة: تحديد قوى السوق الرئيسية وتحديد الطلب في السوق وتحديد الاتجاهات المحتملة لتطوير تكنولوجيا الطاقة المتجددة ووضع معالميد ونديد لتطوير تكنولوجيا الطاقة

\section{المتجددة.}

الـراسة السادسة:

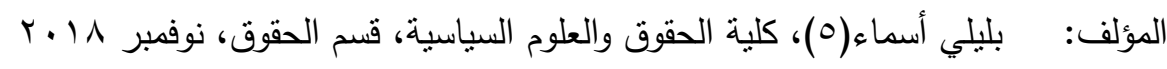
الهدف: انعكاسات تطبيق تقنيات الادارة الالكترونية للمرافق العامة الماهن مجال تقنيات الادارة الالكترونية في المصالح العامة التطبيق:

النتيجة: تطوير مستوى العاملين بالإدارة العامة كأحد اوجه المعادلة الخاصة بترشيد وتحسين الخدمة العمومية

الإراسة السابعة: - مانحين

المؤلف: أحمد محمد المصري، الإدارة الحديثة، الاتصالات، القرارات، الإسكندرية 10 الهدف: أسلوب التحكم في نظم المعلومات واتخاذ القرار في المؤسسة الادرة مجال مؤسسة الثباب الجامعية

النتيجة: نظام المعلومات الإدارية دور كبير وفعال في مختلف المؤسسات وذلك نظرا

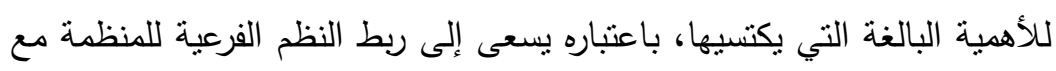
بعضها البعض لبن الإراسة الثامنة: - بعضئ المؤلف: ولهي المختار، نظام المعلومات الإدارية، كلية ادارة الأعمال السودان، اكتوبر r.IV الهدف: الإدارة الالكترونية في الدول العربية 488

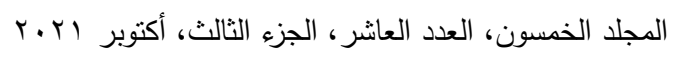

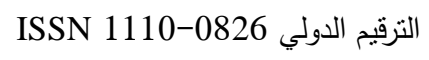
الترقيم الدولي الموحد الإلكتروني 3178-2636 
النتيجة: استخدام تكنولوجيا الاعلام والاتصال في الأداء الإداري، أصبح ضرورة حتمية نظرا للمزايا الكبيرة التي يملكها

المؤلف: عمارة محمد علي عامر، بكالوريوس العلوم الإدارية، جامعة القرآن الكريم والعلوم

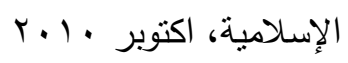
الهدف: نظم المعلومات الإدارية ودورها في نطوير القرارات الإدارية مجال تطبيق على الثركة السودانية للاتصالات المحدودة النطبيق: النتيجة: باستخدام نظم المعلومات الإدارية في الثركة السودانية للاتصالات أدي الي

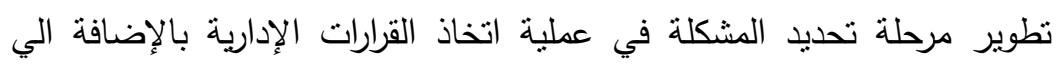
تطوير مرحلة جمع البيانات وتحليلها.

الإراسة العاشرة: -

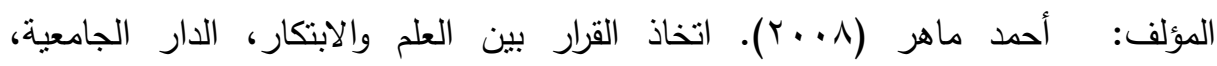
الاسكندرية الهدف: اتخاذ القرار بين العلم والابتكار مجال المنظمات المصرية والعربية والوزارات والحكومات العربية التطبيق: النتيجة: ان القرار يعتمد على المنطق والرشد والتحليل والأساليب العلمية والكمية مستخدما العلم والابتكار .

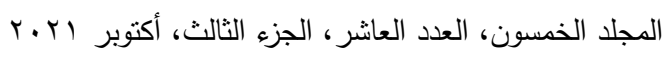

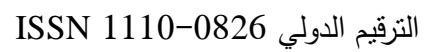

$$
\begin{aligned}
& \text { التزقيم الدولي الموحد الإلكتروني 3178-2636-2كإل }
\end{aligned}
$$




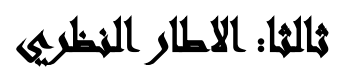

النظم الإدارية (متغير مستقل): سوف نعتمد في قياس نظم المعلومات الادارية

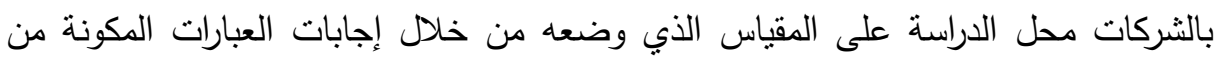

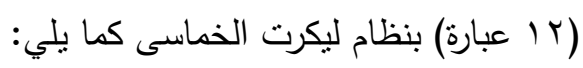

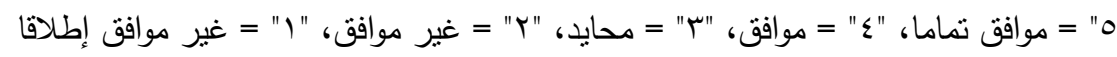
(^ع (Solignac)

نظم دعم اتخاذ القرار (متغير وسيط): سوف نعنمد في في قياس متغير تكنولوجيا المعلومات على المقياس الذي وضع وسوف يقوم الباحث بالتعديل في العبارات المكونة من (r ا عبارة) بما يتفق مع طبيعة الدراسة الحالية والوحدات موضوع الدراسة. (GPuerta (م) Giudice التتمية المستدامة (متغير تابع): سوف يعتمد الباحث في قياس أبعاد التتمية المستدامة

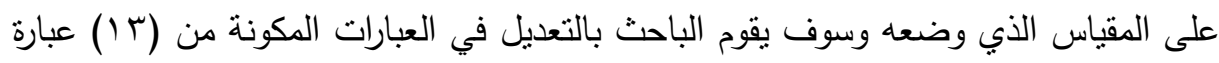

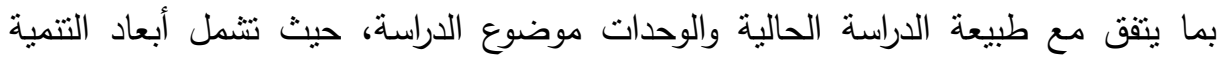

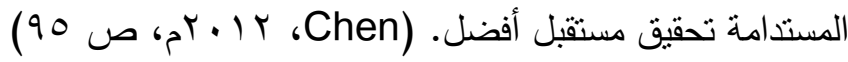

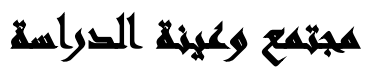

يشمل مجتمع الدراسة جميع العاملين بالثركة الدصرية لخدمات التتبع وتكنولوجيا

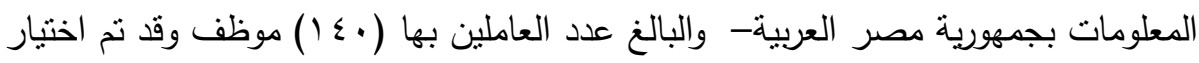
هذه الثركة لكونها الوحيدة بجمهورية مصر العربية التي تعمل على مجال التعال التتع للمركبات والسفن في مصر .وقد تم اختيار عينة عشوائية بسيطة نم احتسابها بأستخدام معادلة ستيفن

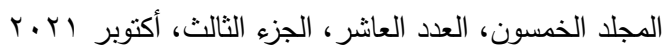

$$
\begin{aligned}
& \text { الترقيم الدولي 0826-08SN 1110 } \\
& \text { الترقيم الدولي الموحد الإكتروني 3178-2636 }
\end{aligned}
$$


ثامبسون (Stephen Thompson) وبالتطبيق بمعامل ثقة (90\%) أي بنسبة خطا تصل الي (\%) (1\%).

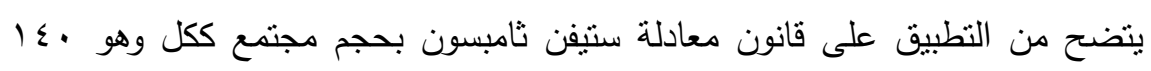

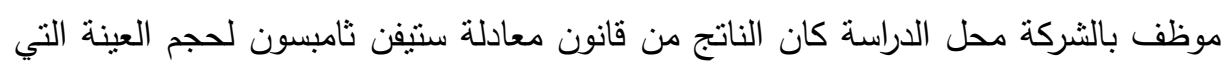

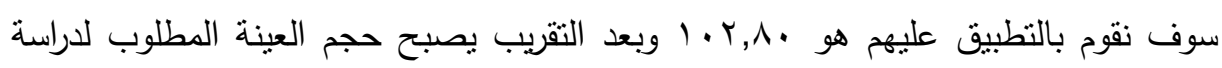

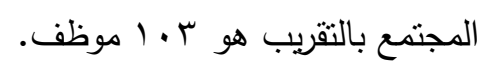

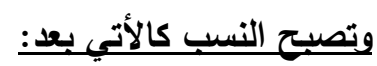

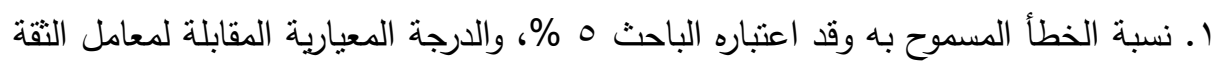

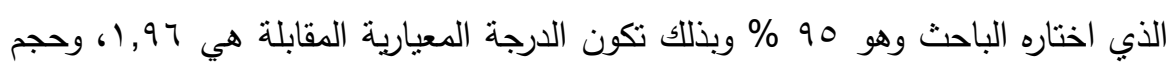

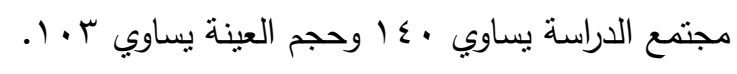

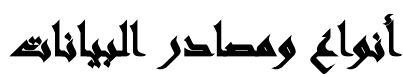

البيانات الثانوية (توصيف المرجعية): قام الدراسة المسحية المكثة للأبحاث والدراسات السابقة، والمراجع العربية والأجنبية والدوريات العلمية، والندوات، والمؤتمرات المتعلقة بمتغيرات

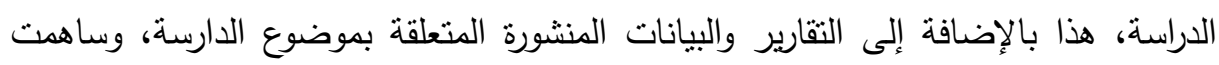
البيانات الثانوية في تكوين الإطار الفكري والفلسفي للاراسة. البيانات الأولية (توصيف عدد الاسئلة): وهي البيانات التي تم الحصول عليها من

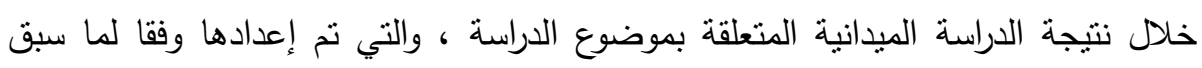

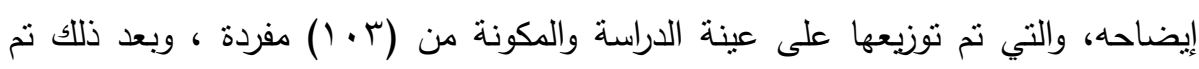

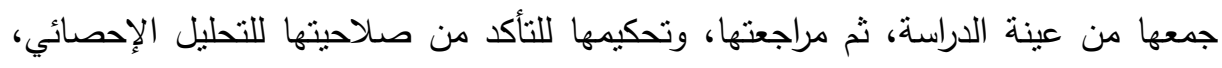
حيث نم اجراء اختبار المصداقية والاعتمادية لقائمة الاستقصاء من خلاد فئهاس وناس معامل

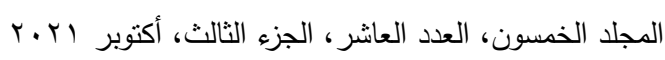

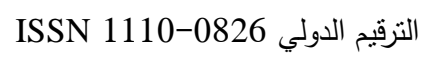

$$
\begin{aligned}
& \text { الترقيم الدولي الموحد الإلكتروني 3178-2636 }
\end{aligned}
$$




$$
\begin{aligned}
& \text { مجلة العلوم البيئية } \\
& \text { كلية الدراسات العليا والبحوث البيئة - جامعة عين شمس لئية } \\
& \text { وليد محمد عبد الخالق بكر وآخرون الئنة }
\end{aligned}
$$

الصدق والثبات (ألفاك ونباخ)، وذلك بغرض التأكد من صلاحية المقياس وقدرته على قياس الظاهرة البحثية وذلك لتحديد مدى صحة المقاييس المستخدمة، وبحث مدى إمكانية الاعنماد على نتائج الدراسة الميدانية في تعميم ما سيتم التوصل إلئ مديه.

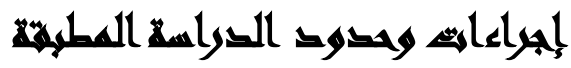

الحدود المكانية :سوف يتم تطبيق هذه الدراسة على شركات التتبع بجمهورية مصر العربية (الثركة المصرية لخدمات التتبع وتكنولوجيا المعلومات). الحدود الموضوعية: تركز الدراسة بصفة أساسية على ثلاثة متغيرات وهما (تكنولوجيا المعلومات الإدارية ونظم دعم اتخاذ القرار والتتمية المستدامة).

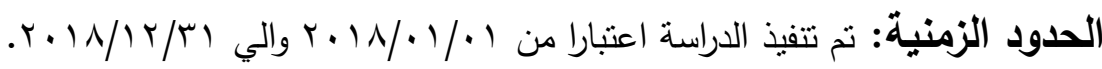

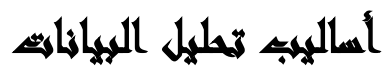

تم اجراء التحليل بعد إتمام اجراءات جمع الاستقصاء، وباستخدام برنامج الحزمة المتقدمة للتحليل الإحصائي SPSS وبواسطة الإصدار العشرين بحيث تم استخدام الأدوات التحليلية

ا- اختبار الثبات من خلال معامل ألفا كرونباخ Alpha Cronbach’s لاختبار ثبات

$$
\text { متغيرات الدراسة. }
$$

r- اختبار صدق الإتساق الداخلي من خلال معامل إرتباط بيرسون لأبعاد الاستبيان.

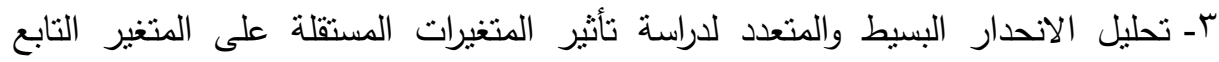

$$
\text { للتحقق من صحة فروض الدراسة. }
$$

492

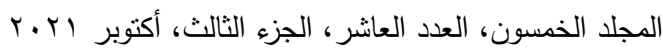

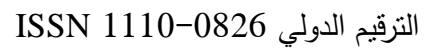

$$
\begin{aligned}
& \text { الترقيم الدولي الموحد الإلكتروني 3178-2636 }
\end{aligned}
$$


أولاً: قياس الاعتمادية (الثبات والصدق للاستبيان): قام الباحث بالتحقق من ثبات وصدق أداة الدراسة للنأكد من صلاحية الأداة للنطبيق. 1-الثبات:معامل ثبات ألفا كرونباخ (Alpha Cronbach): للتحقق من ثبات الاستنيان لإمكانية الاعتماد على نتائجه استخدم الباحث معادلة ألفا كرونباخ وتوضح الجداول التالية معاملات الثبات الناتجة باستخدام هذه المعادلة. جدول (1): ثبات عبارات أبعاد متغير نظم المعلومات الإدارية

\begin{tabular}{|c|c|c|}
\hline قيمة آلفا & عدد العبارات & 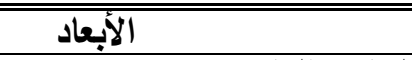 \\
\hline., $99 \mathrm{r}$ & $V$ & لجانب المادي \\
\hline$\cdot, 9 \wedge 0$ & 0 & لجانب الذهنى \\
\hline$\cdot, 99 \xi$ & TY & جمالى نظح الدعلومات الإدارية \\
\hline
\end{tabular}

يتضح من الجدول السابق لثبات عبارات أبعاد متغير نظم المعلومات الإدارية أن قيم

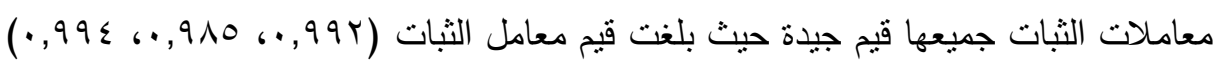
لأبعاد متغير نظم المعلومات الإدارية (الجانب المادي، الجانب الذهني، إجمالي نظم

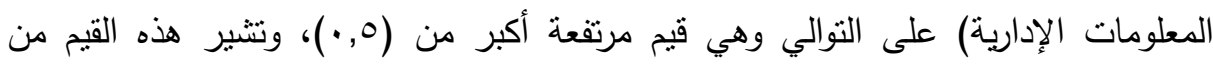

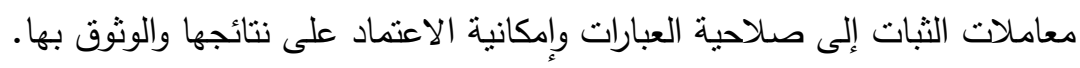
جدول (ץ): ثبات عبارات أبعاد متغير نظم دعم إتخاذ القرار

\begin{tabular}{|c|c|c|}
\hline قيمة ألفا & عدد العبارات & الأبعاد \\
\hline$\cdot, 9 \wedge \varepsilon$ & 0 & إيجاد القرار المناسب \\
\hline$\cdot, 9 \cdot 4$ & r & التوقيت المناسب للقرار \\
\hline$\cdot, 909$ & 0 & الصلاحية التتفيذية للقرار \\
\hline$\cdot, \wedge \nmid \wedge$ & Ir & إجمالى متغير نظح دعم إتخاذ القرار \\
\hline
\end{tabular}

يتضح من الجدول السابق لثبات عبارات أبعاد منغير نظم دعم إنخاذ القرار أن قيم

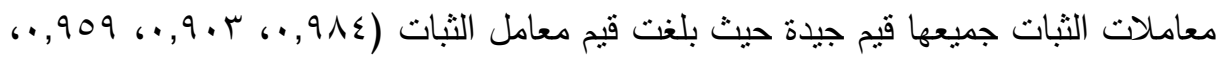

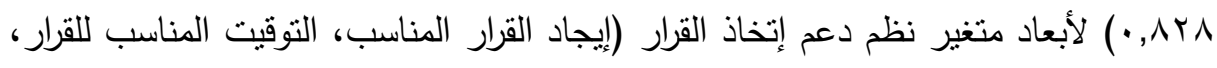

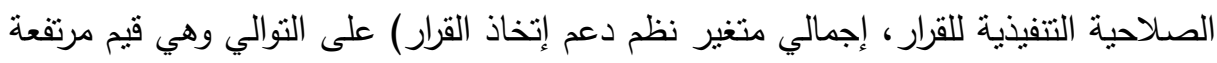

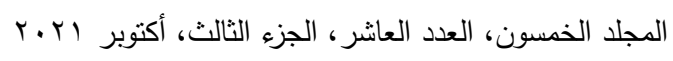

التزقيم الدولي 0826- ISSN 1110 الترني

$$
\text { الترقيم الدولي الموحد الإلكتروني 3178-2636 }
$$


أكبر من (0,·)، وتتشير هذه القيم من معاملات الثبات إلى صلاحية العبارات وإمكانية

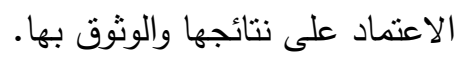

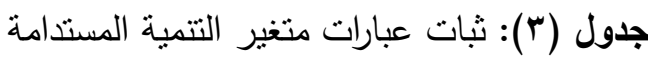

\begin{tabular}{|c|c|c|}
\hline قَيمة آلفا & عدد العبارات & آبعاد التتميةٌ المستدامة \\
\hline$\cdot, 910$ & 0 & التنمية \\
\hline$\cdot, 9 \wedge \mathrm{V}$ & $\Lambda$ & الاستدامة \\
\hline$\cdot, 994$ & $\pi$ & إجمالى متغير التتمية المستدامة \\
\hline
\end{tabular}

يتضح من الجدول السابق لنبات عبارات متغيرات الاستبيان أن قيم معاملات الثبات

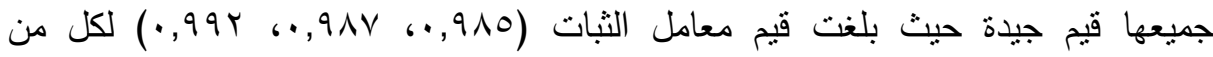

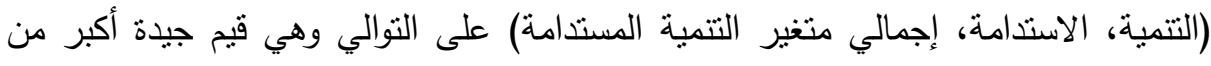

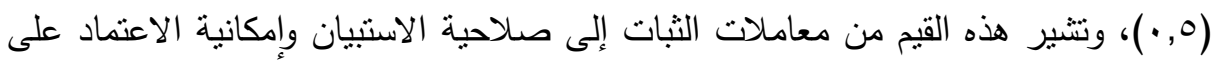
نتائجه والوثوق به. r

جدول (؛): صدق الاتساق الداخلي لأبعاد متغير نظم المعلومات الإدارية

\begin{tabular}{|c|c|c|}
\hline الدلالة المعنوية & معامل ارتباط بيرسون & الأبعاد \\
\hline$\cdot, \cdots$ & $\left({ }^{* *}\right) \cdot, 991$ & الجانب المادي \\
\hline$\cdot, \cdots$ & $\left({ }^{(*)}\right) ., 991$ & الجانب الذهني \\
\hline
\end{tabular}

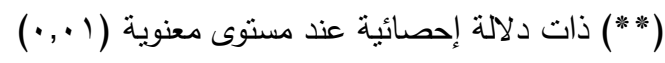

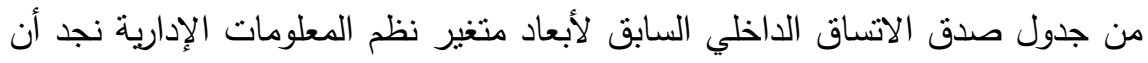
معامل الارتباط بين أبعاد متغير نظم المعلومات الإدارية وإجمالي البعد ذات دلالية لإلة إحصائية

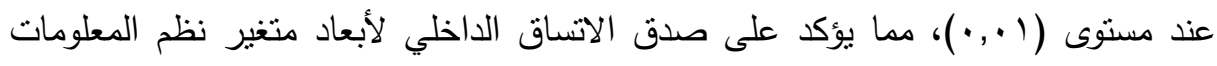

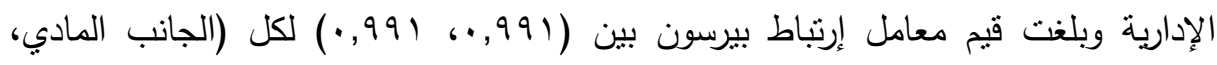
الجانب الذهني) على التوالي.

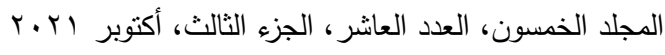

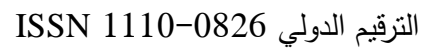

$$
\begin{aligned}
& \text { التزقيم الدولي الموحد الإلكتروني 3178-2636-2082 }
\end{aligned}
$$


جدول (•): صدق الاتساق الداخلي لأبعاد متغير نظم دعم إتخاذ القرار

\begin{tabular}{|c|c|c|}
\hline الالالة المعنوية & معامل ارتباط بيرسون & الأبعاد \\
\hline$\cdot, \cdots$ & $\left.\left({ }^{* * *}\right) \cdot, 7 \mu\right\urcorner$ & إيجاد القرار المناسب \\
\hline$\cdot, \ldots$ & $\left({ }^{* * *}\right),, 7.0$ & التوقيت المناسب للقرار \\
\hline$\cdot, \ldots$ & $(* *),, 779$ & الصلاحية التتفيذية للقرار \\
\hline
\end{tabular}

(***) ذات دلالة إحصائية عند مستوى معنوية (1 ., )

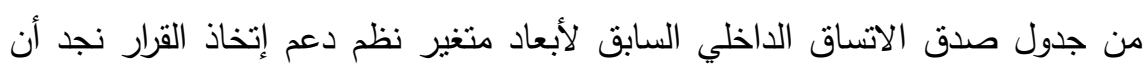

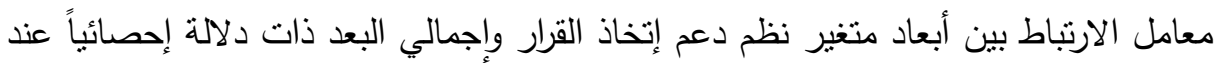

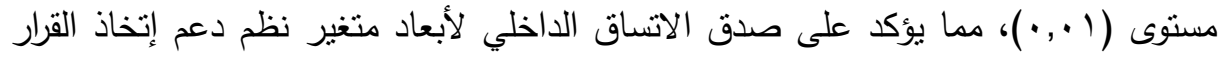

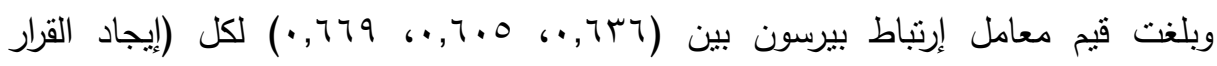

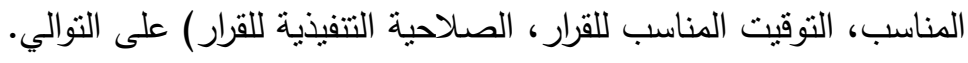

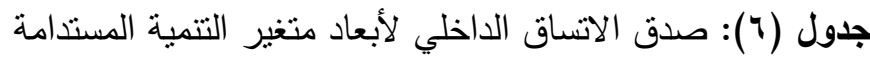

\begin{tabular}{|c|c|c|}
\hline الدلالة المعنوية & معامل ارتباط بيرسون & الأبعاد \\
\hline$\cdot, \ldots$ & $(* *) \cdot, 99 \mathrm{r}$ & التنمية \\
\hline$\cdot, \ldots$ & $(* *) ., 994$ & الاستدامة \\
\hline
\end{tabular}

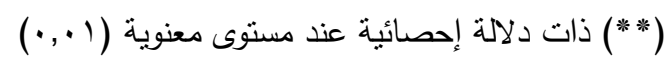

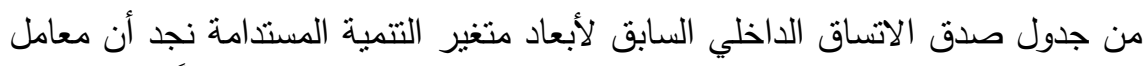

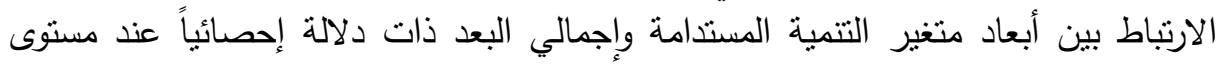

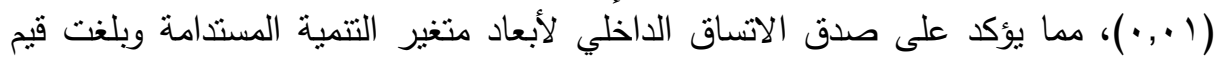

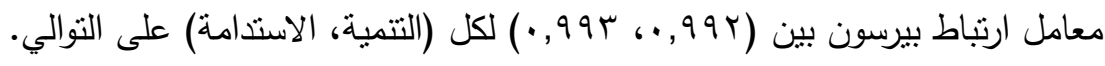
جدول (V): صدق الاتساق الداخلي لمتغيرات الاستنيان

\begin{tabular}{|c|c|c|}
\hline الدالة المعنوية & معامل ارتباط بيرسون & أبعاد الاستبيان \\
\hline,$+ \cdots 1$ & $(* *) \cdot, 9 \vee$. & المتغير المستقل: نظم المعلومات الإدارية \\
\hline$\cdot, \ldots 1$ & $(* *) \cdot, V R r$ & المتغير الوسيط: نظم دعم اتخاذ القرار \\
\hline$\cdot, \ldots 1$ & $(* *) \cdot, 97 r$ & المتغير التابع: التتمية المستدامة \\
\hline
\end{tabular}

المجلد الخمسون، العدد العاشر ، الجزء الثالث، أكتوبر (r.r.

التزقيم الدولي

$$
\text { الترقيم الدولي الموحد الإلكتروني 3178-2636 التروب }
$$


من جدول صدق الاتساق الداخلي السابق لمتغيرات الاستنيان نجد أن معامل الارتباط

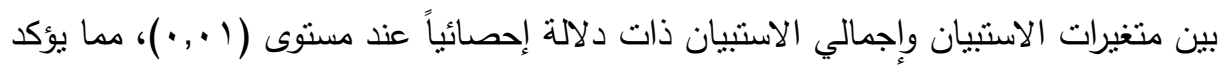
على صدق الاتساق الداخلي لمتغيرات الاستبيان وبلغت قيم معامل ارتباط بيرسون بين الانين

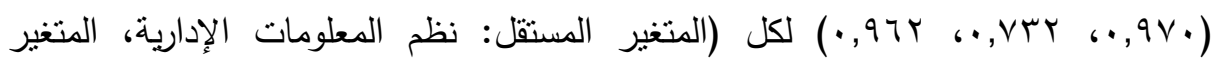
الوسيط: نظم دعم اتخاذ القرار، المتغير التابع: التتمية المستدامة) على التوالي.

\section{لمتأيج الصراسة}

الفرض الأول: يوجد أثر معنوي لإعادة هندة نظم المعلومات الإدارية محل الدراسة كمتغير

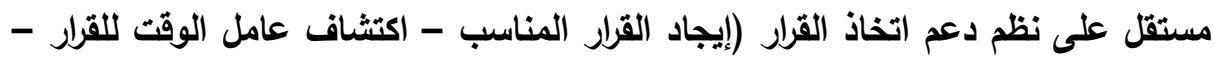

الصلاحية التنفيذية للقزار) كمتغير وسيط. جدول (^):اختبار الانحدار البسيط لتأثثر نظم المعلومات الإدارية على نظم دعم إتخاذ القرار

\begin{tabular}{|c|c|c|c|c|c|c|c|}
\hline المعنوية & ق قيمة & 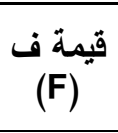 & $\begin{array}{l}\text { التحايد } \\
\text { (R2) } \\
\left(R^{2}\right)\end{array}$ & $\begin{array}{c}\text { الإرتباط } \\
\text { (R) } \\
\text { (R) }\end{array}$ & $\begin{array}{l}\text { الإنحدار } \\
\text { (B) } \\
\text { (B) }\end{array}$ & المتغير التابع & المستقلير \\
\hline$\cdot, \ldots$ & $v, v \leqslant 1$ & $09,9 Y V$ & $\overline{e, r V Y}$ & (.,7). & 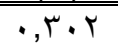 & نظم دعم القرار & النظ الإدارية \\
\hline
\end{tabular}

يتضح من الجدول السابق لتحليل الانحدار الخطي البسيط لتأثير نظم المعلومات الإدارية

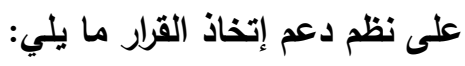

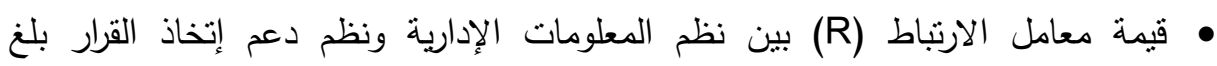

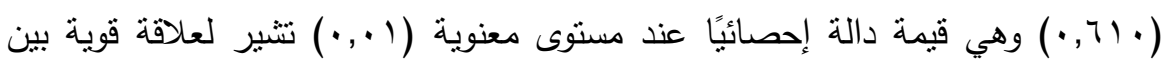
نظم المعلومات الإدارية ونظم دعم إتخاذ القرار وكانت مستوى المعنوية للعلاقة ( . . ., .).

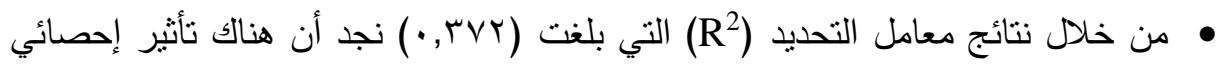

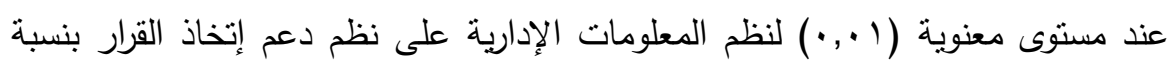
(\%rV,r)

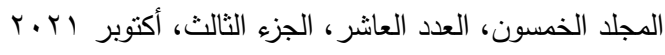

$$
\begin{aligned}
& \text { الترقيم الدولي 0826-08SN 1110 } \\
& \text { الترقيم الدولي الموحد الإكتروني 3178-2636 }
\end{aligned}
$$




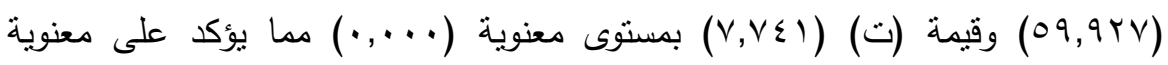

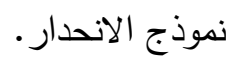

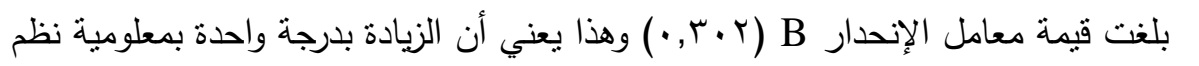

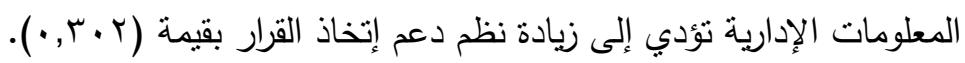

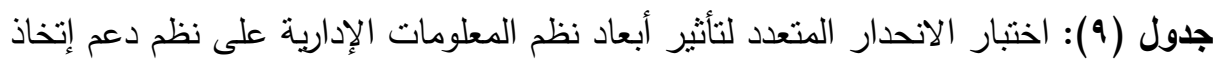

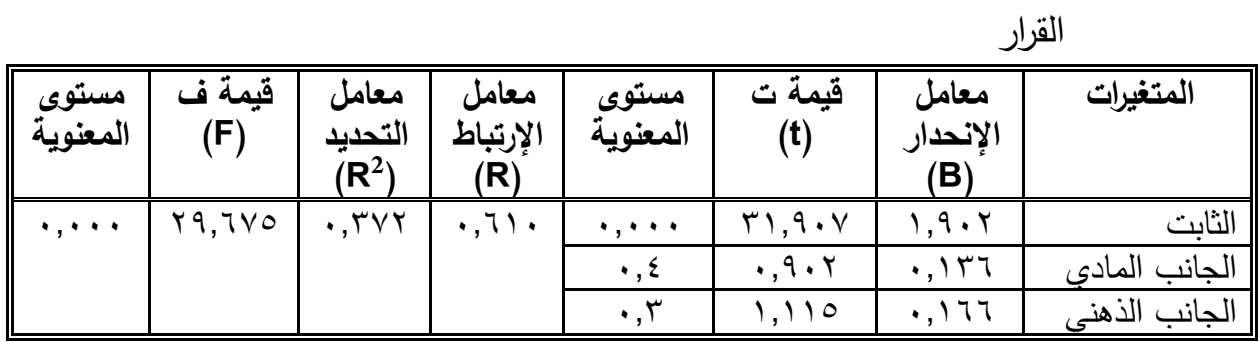

يتضـح مـن الجدول السـابق لنتائج تحليـل الانحدار المتعدد لدراسـة تأثنير أبعـاد نظم

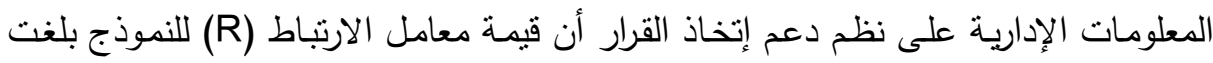

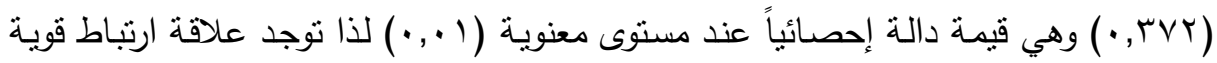
بين أبعاد نظم المعلومات الإدارية ودعم إتخاذ القرار .

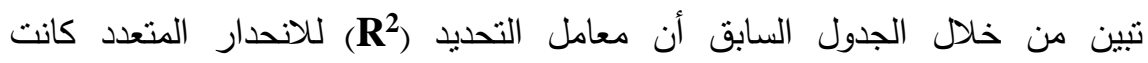
(• (1, •) وهناك تتبؤ بتأثير أبعاد نظم المعلومات الإدارية على دعم إتخاذ القرار بنسبة

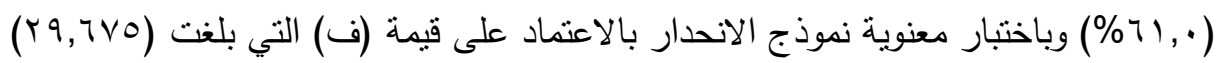

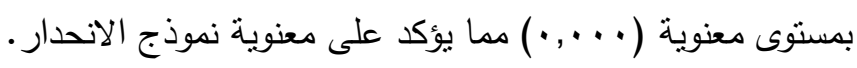

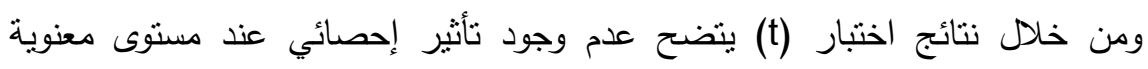

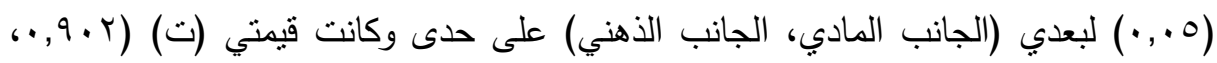

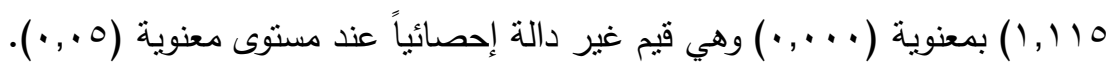


مما سبق ثبت صحة الفرض الأول: يوجد أثز معنوي لإعادة هندسة نظم المعلومات

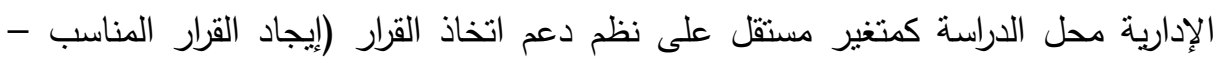
اكتثاف عامل الوقت للقرار - الصلاحية التفيذية للقرار ) كمتغير وسيط. الفرض الثاني: يوجد أثر معنوي لأبعاد نظم المعلومات الادارية محل الاراسة كمتغيرات

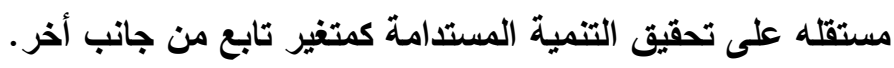

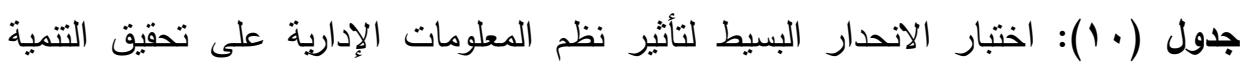

\begin{tabular}{|c|c|c|c|c|c|c|c|}
\hline & & & & \multicolumn{4}{|c|}{ المستدامة } \\
\hline المعنوية & $\begin{array}{c}\text { قيمة } \\
\text { (t) }\end{array}$ & قيمة ف & $\begin{array}{l}\text { التحايد } \\
\text { معامل } \\
\left(R^{2}\right)\end{array}$ & $\begin{array}{c}\text { الإرتباط } \\
\text { (R) } \\
\text { (R) }\end{array}$ & الإنحدار & التابع & المستقلي \\
\hline$\cdot, \ldots$ & $r \varepsilon, \cdot 9 V$ & דו, & •, AOr & & • & المستدأمة & المعلوماتية \\
\hline
\end{tabular}

يتضح من الجدول السابق لتحليل الانحدار الخطي البسيط لتأثير نظم المطومات

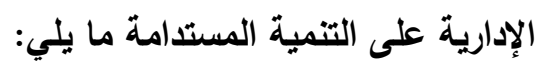

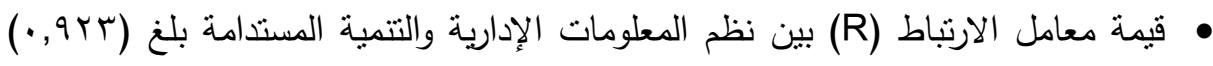

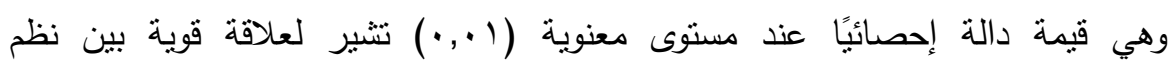
المعلومات الإدارية والتتمية المستدامة وكانت مستوى المعنوية للعلاقة ( ( .,. •). • من خلال نتائج معامل التحديد (R2) التي بلغت (ROr, · • ) نجد أن هناك تأثير إحصائي

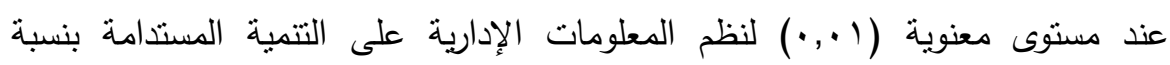

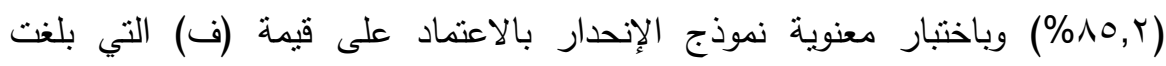

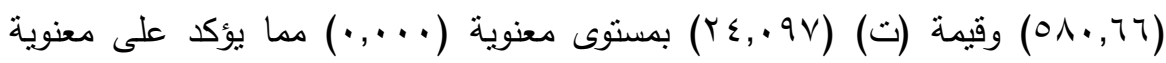
نموذج الانحدار 


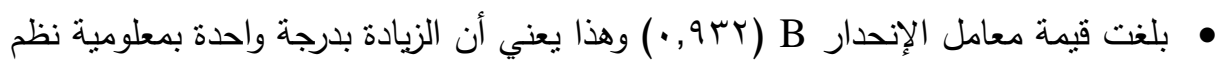

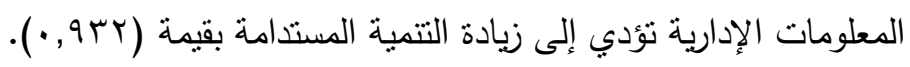

جدول (11): اختبار الانحدار المتعدد لتأثير أبعاد نظم المعلومات الإدارية على تبلى تحقيق التتمية المستدامة

\begin{tabular}{|c|c|c|c|c|c|c|c|}
\hline مستوية & قيمة ف & $\begin{array}{l}\text { التحديد } \\
\text { (R2) } \\
\left(R^{2}\right)\end{array}$ & $\begin{array}{c}\text { الإرتباط } \\
\text { (R) } \\
\text { (R) }\end{array}$ & المعنوية & قيمة ت & $\begin{array}{l}\text { الإنحدار } \\
\text { (B) } \\
\text { (B) }\end{array}$ & المتغيرات \\
\hline \multirow{3}{*}{$\cdot, \cdots$} & \multirow{3}{*}{ דוזד, •090 } & \multirow{3}{*}{ - 9 GY } & \multirow{3}{*}{$\cdot, 97}$. & $\cdot, \cdot \varepsilon$ & $r, \cdot \leqslant 1$ & $\cdot, \wedge \wedge$ & الثابت \\
\hline & & & & $\cdot, \cdot$ & $0, .90-$ & $\cdot, 00 Y-$ & الجادي \\
\hline & & & & $\cdot, \cdots$ & $M, v \leq 1$ & $1, \varepsilon V r$ & الألهنب \\
\hline
\end{tabular}

يتضـح مـن الجدول السـابق لنتائج تحليـل الانحدار المتعدد لدراسـة تأثنير أبعـاد نظم

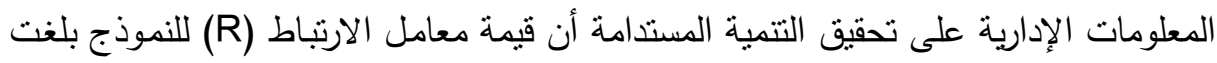

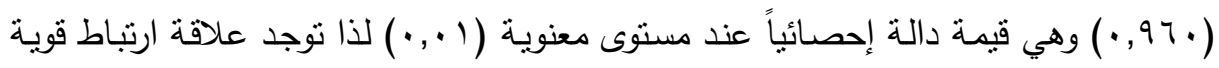
بين أبعاد نظم المعلومات الإدارية وتحقيق التتمية المستدامة.

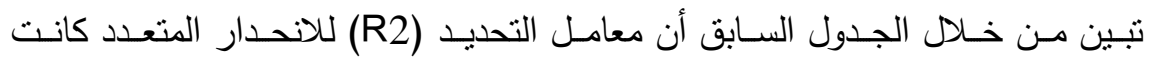

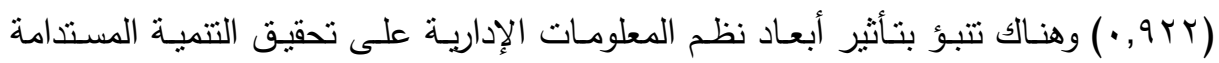

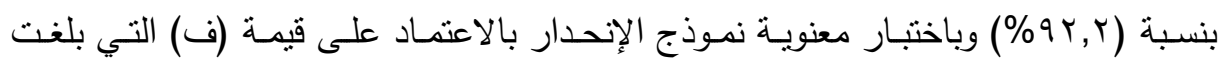

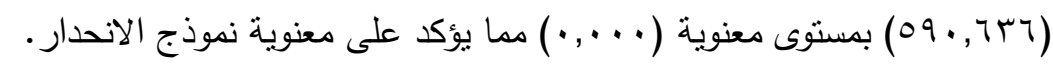

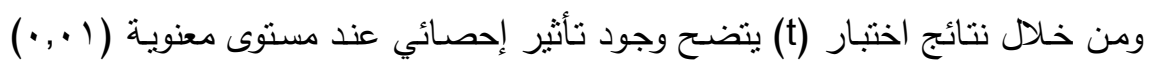

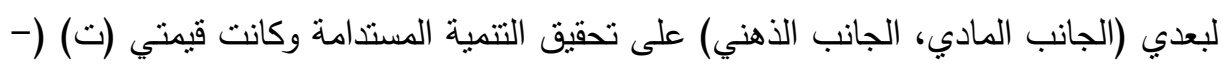

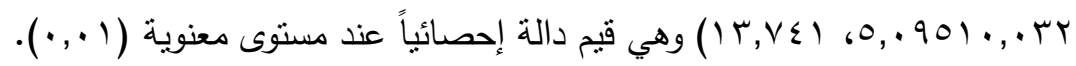


مما سبق ثبت صحة الفرض الثاني: يوجد أثر معنوي لأبعاد نظم المطلومات الادارية محل الدراسة كمتغيرات مستقله على تحقيق التنمية المستدامة كمتغير تابع من جانب أخر.

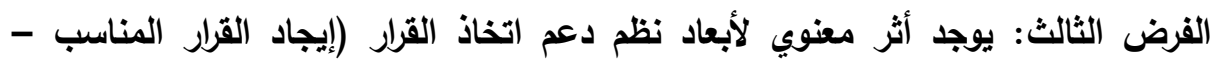

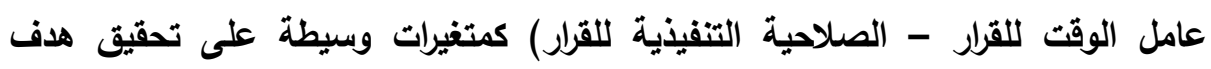
التنمية المستدامة وذلك كمتغير تابع. جدول (r)): اختبار الانحدار البسيط لتأثثر نظم دعم إتخاذ القرار على تحقيق التتمية المستدامة المابنا

\begin{tabular}{|c|c|c|c|c|c|c|c|}
\hline المعنوية & تق تيمة & قيمة ف & $\begin{array}{l}\text { التحديد } \\
\text { (R2) } \\
\left(R^{2}\right)\end{array}$ & $\begin{array}{c}\text { الإرتباط } \\
\text { (R) } \\
\text { (R) }\end{array}$ & 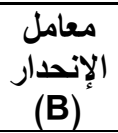 & المتغير التابع & المستقِل \\
\hline$\cdot, \ldots$ & $v, \cdot 7 \lambda$ & $\leqslant 9,901$ & וTr, &., $0 \vee 0$ & $1,1 \vee r$ & المستخامية & نظم دعم القرار \\
\hline
\end{tabular}

يتضح من الجدول السابق لتحليل الانحدار الخطي البسيط لتأثير نظم دعم إتخاذ القرار على التنمية المستدامة ما يلي: من البالئ

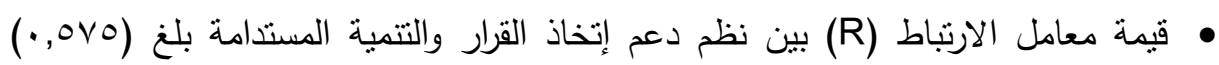

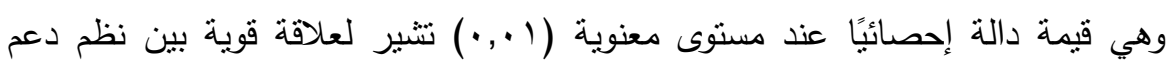
إتخاذ القرار والتتمية المستدامة وكانت مستوى المعنوية للعلاقة ( ( . , •).

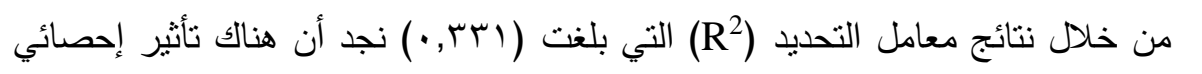

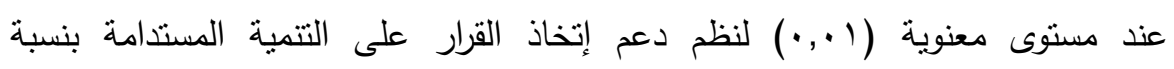

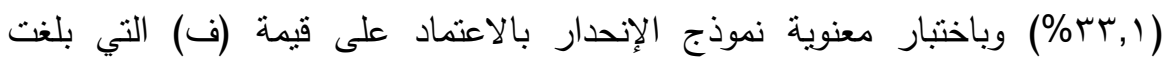

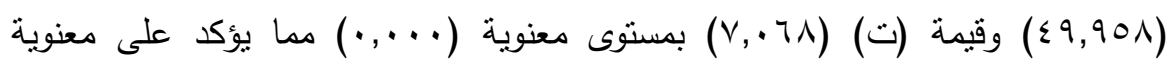

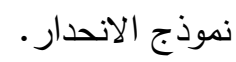

بلغت قيمة معامل الإنحدار B B B (, V ) وهذا يعني أن الزيادة بدرجة واحدة بمعلومية نظم

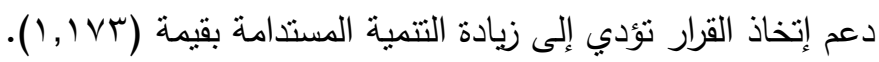

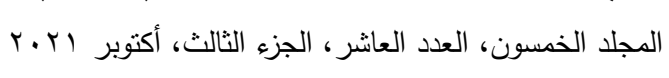

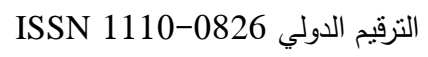

$$
\text { الترقيم الدولي الموحد الإلكتروني 3178-2636 الترول }
$$


مجلة العلوم البيئية

كلية الدراسات العليا والبحوث البيئية - جامعة عين شمس لئن

وليد محمد عبد الخالق بكر وآخرون الئن

جدول (r ا I): اختبار الانحدار المتعدد لتأثير أبعاد نظم دعم إتخاذ القرار على تحقيق التتمية المستدامة المارة

\begin{tabular}{|c|c|c|c|c|c|c|c|}
\hline المعنوية & قيمة ف & $\begin{array}{l}\text { التحديد } \\
\text { (R2) } \\
\left(\mathbf{R}^{2}\right)\end{array}$ & $\begin{array}{c}\text { الإرتباط } \\
\text { (R) } \\
\text { (R) }\end{array}$ & المعنوية & 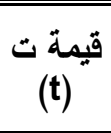 & $\begin{array}{l}\text { الإنحدار } \\
\text { (B) } \\
\text { (B) }\end{array}$ & المتغيرات \\
\hline \multirow{4}{*}{$\cdot, \cdots$} & \multirow{4}{*}{$r \cdot r, 07$} & \multirow{4}{*}{$\cdot, 9 \cdot r$} & \multirow{4}{*}{ •,90. } & $\cdot, \ldots r$ & $r, I \wedge r$ & קדז, & الثابت \\
\hline & & & & $\cdot, 1$ & $\varepsilon, \Gamma \leqslant \Gamma$ &., 017 & إيجاد القرار المناسب \\
\hline & & & & $\cdot, \cdots$ & $1,9 \leq 1$ & $\cdot, .07$ & التوقيت المناسب \\
\hline & & & & & ס ט, r & $\cdot, r V V$ & الصلاحية التنفيذية \\
\hline
\end{tabular}

يتضـح من الجدول السابق لنتائج تحليل الانحدار المتعدد لدراسـة تأثثر أبعاد نظم دعم

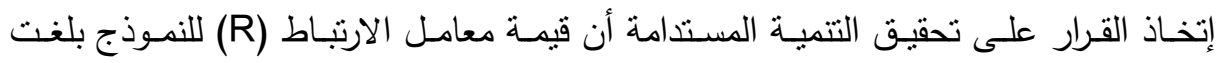

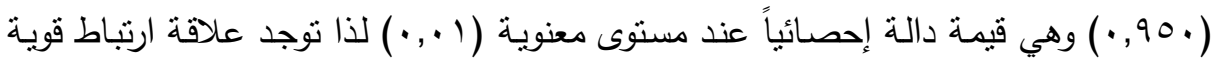
بين أبعاد نظم دعم إتخاذ القرار وتحقيق التتمية المستدامة.

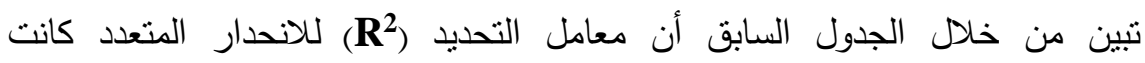

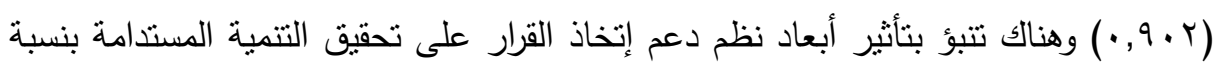

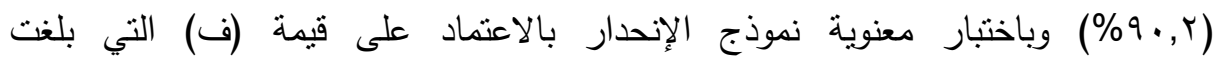

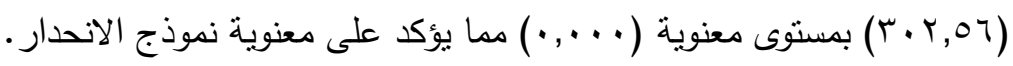

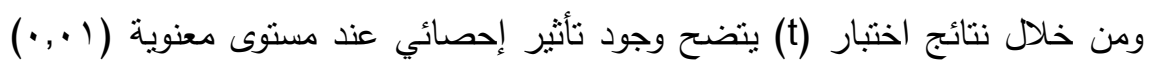

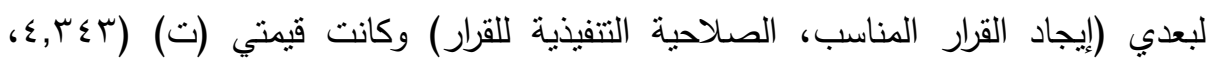
هYr,r) بمعنوية ( . ., •) بينما لم يكن هناك تأثثر معنوي لبعد (التوقيت المناسب للقرار)

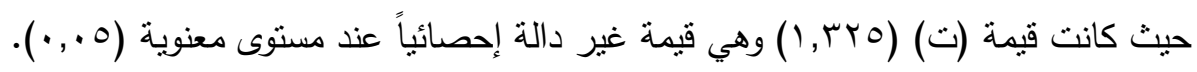

التزقيم الدولي الترقيم الدولي الموحد الإلكتروني 3178-2636 
مما سبق ثبت صحة الفرض الثالث: يوجد أثز معنوي لأبعاد نظم دعم اتخاذ القرار

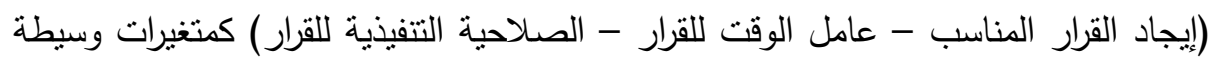
على تحقيق هدف التتمية المستدامة وذلك كمتغير تابع.

\section{تمعيامت الستواسم}

() ربط النظم الفرعية للشركات مع بعضها في نظام منكامل بما بسمح بتدفق البيانات

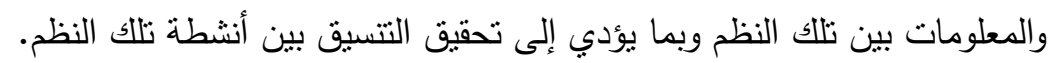
r) ابراز أهمية دور إدارة التخطيط والتتسيق والمتابعة من حيث القرارات الاستراتيجية. r) توفير المعلومات اللازمة لأغراض التخطيط والرقابة في المكان والوقت والثكل المناسب.

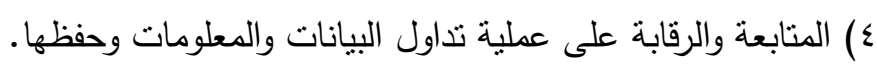

\section{مرايج التوراهة}

أثر نظم المعلومات على تفعيل اليقظة دراسة استراتيجية -جامعة أم البواقي - اعداد جوني

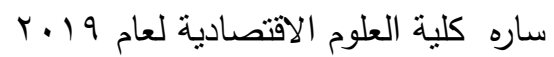

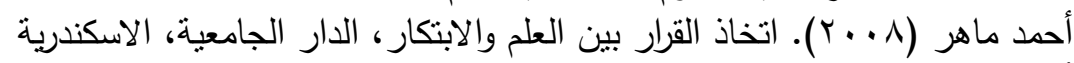

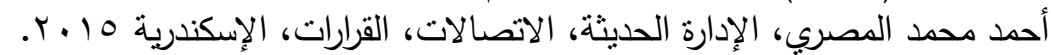

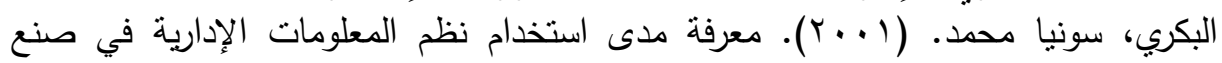

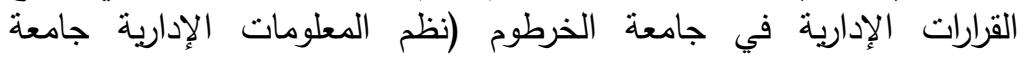
الإسكندرية).

تصميم طرق تطوير تقنيات الطاقة المتجددة، جامعة كأوانس للتكنولوجيا.(ع الـ ب). الاقتصاد

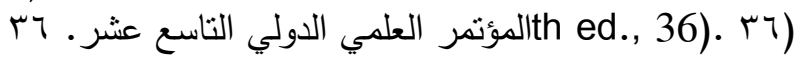

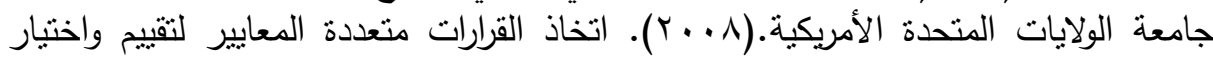

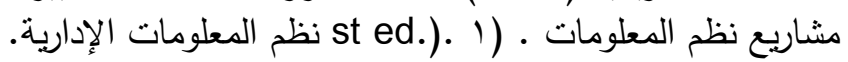

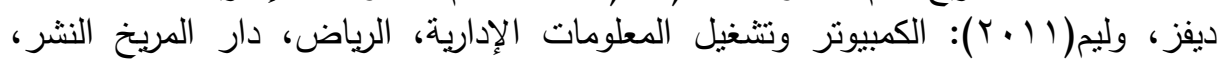

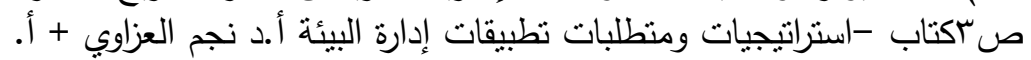

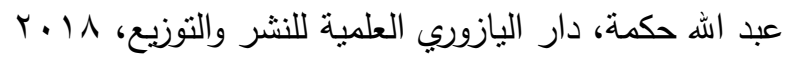

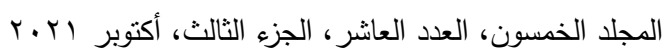

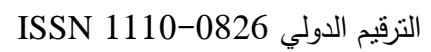

$$
\begin{aligned}
& \text { الترقيم الدولي الموحد الإلكتروني 3178-2636 }
\end{aligned}
$$




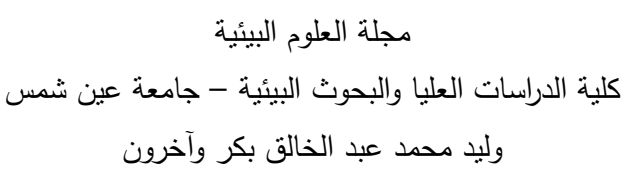

ريتشارد واتسون-قسم نظم المعلومات الإدارية، كلية ادارة الأعمال بالولايات المتحدة الأمريكية،

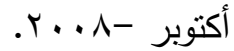

محمود صبح، نظام BLISS في الإدارة المعاصرة، جامعة عين شمس، دار السلام للطباعة،

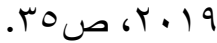

مكتبة كلية الاقتصاد والإدارة القاهرة. (9 (ب). مقدمة في نظم المعلومات الإدارية. كلية الاقتصاد والإدارة. - الإن

Chen, A.J.; Boudreau, M.C. Watson, R.T. Information systems and ecological sustainability. J. Syst. Inform. Technol. 2008, 10, 186-201.

Halleck, K. Designing routes of development of renewable energy technologies. Procardia Soc. Behave. Sci. 2014, 156, 58$62 .$.

John. Areal Faculty of Economics and Management, University of Szczecin, Mickiewicz a 64, 71-101 Szczecin, Poland 24 February 2019.

Watson, R.T.; Boudreau, M.C.; Chen, A.J. Information systems and environmentally sustainable development: Energy informatics and new directions for the IS community. MIS Q. 2010, 23-38.

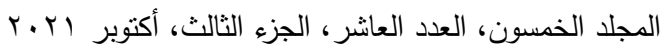

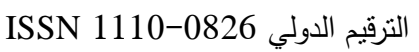

$$
\begin{aligned}
& \text { التزقيم الدولي الموحد الإلكتروني 3178-2636 }
\end{aligned}
$$




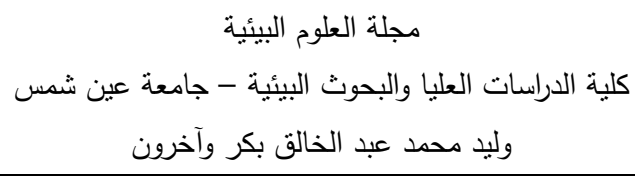

\section{DECISION SUPPORT AS AN INTERMEDIATE}

VARIABLE BETWEEN REENGINEERING OF

ADMINISTRATIVE SYSTEMS AND ACHIEVING

SUSTAINABLE DEVELOPMENT

APPLIED STUDY ON TRACKING COMPANIES IN

EGYPT

\section{Waled M. A. Bakr ${ }^{(1)}$; Mahmoud M. Sobh ${ }^{(2)}$ and Moussa I. Moussa ${ }^{(3)}$}

1) Post Grad. Student, Faculty of Graduate Studies and Environmental Research, Ain Shams University 2) Faculty of commerce, Ain Shams University 3) 6 October University

\section{ABSTRACT}

The study aims to identify the role of administrative systems within tracking companies in the Arab Republic of Egypt and how they affect decision-making support systems through the availability of all available alternatives to choose the optimal alternative to achieve sustainable development, and in order to achieve the objectives of the study, the inductive approach was used in the theoretical study and the preparation of the field side on a list The questionnaire directed to the sample items, which amount to 103 items, and statistical analysis was used to ensure the validity of the study hypotheses.

The study found the following results:

1- The first main hypothesis has been proven correct, which is correct, correct, correct, correct, correct, correct, correct, correct, correct, correct, correct, correct and intermediate.

2- The second main hypothesis is validated: it exists at another level.

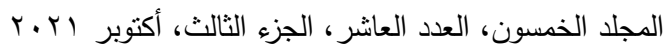

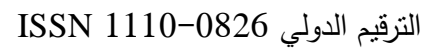

$$
\begin{aligned}
& \text { التزقيم الدولي الموحد الإلكتروني 3178-2636-2082 }
\end{aligned}
$$




$$
\begin{aligned}
& \text { مجلة العلوم البيئية } \\
& \text { كلية الدراسات العليا والبحوث البيئية - جامعة عين شمس لئس } \\
& \text { وليد محمد عبد الخالق بكر وآخرون }
\end{aligned}
$$

3- Prove the validity of the third main hypothesis: There is a significant effect of including decision support systems (finding the appropriate decision - the right time for the decision - valid for the decision) as intermediate variables to achieve the dependent sustainable development goal as a dependent variable.

Among the most important recommendations made by researchers are the following:

1. The link between the common systems and the integrated systems in an integrated system, allowing the flow of data and information between those systems and the implementation of monitoring and communication between the systems of electronic systems.

2. Highlight the role of the Planning and Follow-up Department from the beginning.

3. Providing information for planning and time purposes in the appropriate place, time and form.

4. The process of monitoring and transferring the process of circulating data and information contained in the episode.

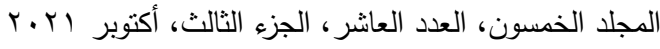

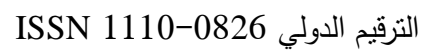

$$
\begin{aligned}
& \text { التزقيم الدولي الموحد الإلكتروني 3178-2636 }
\end{aligned}
$$

